\author{
ORDINAL INDEPENDENCE IN \\ NON-LINEAR UTILITY THEORY \\ Jerry G. Green \\ $* *$ \\ Bruno Jullien \\ May 1988 \\ $N^{\bullet} 8818$
}

Forthcoming : Journal of Risk and Uncertainty

* Harvard University

** CEPREMAP

This research was supported by National Science Foundation grant number IRI-85-07291. The authors thank Mark Machina and Larry Epste in for helpful advice and comments. Jerry Green acknowledges support from the John Simon Guggenheim Memorial Foundation. Bruno Jullien gratefully acknowledges financial support from the Sloan Foundation. 


\section{ORDINAL INDEPENDENCE IN NON-LINEAR UTILITY THEORY}

\section{A BSTRACT}

Individual behavior under uncertainty is characterized using a new axiom, ordinal independence, which is a weakened form of the von NeumannMorgenstern independence axiom. It states that if two distributions share a "tail" in common, then this tail can be modified without altening the individual's preference between these distributions. Preference is determined by the tail on which the distributions differ. This axiom implies an appealing and simple functional form for a numerical representation of preferences. It generalizes the form of "anticipated utility", and it explains some we11-known forms of behavior, such as the Friedman-Savage paradox, that anticipated utility cannot.

Keywords : Choice under uncertainty, independence axiom, non-liriear utility JEL code : 020

\section{INDEPENDANCE ORDINALE EN THEORIE NON-LINEAIRE DE L'UTILITE}

\section{RESUME}

Le comportement d'un individu en face de l'incertain est caractérisé au moyen d'un nouvel axiome, l'indépendance urdinale. Cet axiome est une version affaiblie de l'axiome d'indépendance de von Neumann-Morgenstern. Il stipule que si les cumulatives de deux distributions ont une "queue" en commun, cette queue peut être modifiée sans altérer les préférences de $l$ individu entre les distributions. Les préférences sont déterminées par la portion des cumulatives sur laquelle les distributions diffèrent. Cet axiome implique comme représentation numérique des préférences une forme fonctionnelle simple et attractive. Cette forme gériéralise la forme de "l'utilité anticipée", et permet de rendre compte de certains types bien connus de coraportement, tel que le paradoxe de Friedmann-Savage, que la théorie de l'utilité anticipée ne peut pas expliquer.

Mols clef : Choix sous incertitude, axione d'indépendance, utilité nonlinéaire

Code JEI : 020 


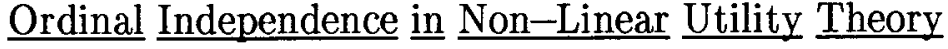

by Jerry R. Green and Bruno Jullien

\section{Introduction}

Recent research in the theory of individual decision making under uncertainty has developed in three directions. All of these are outgrowths of and reactions to the empirical refutation of expected utility theory that is widely acknowledged.

First, there are attempts to describe the decision making process by examining aspects other than the probability distribution over the ultimate payoffs. Research in this direction uses variations in the description of the decision problem, the temporal resolution of the uncertainty or of the payoffs themselves, as important ingredients that can affect the individuals' choice. ${ }^{1}$

Second, there are models that look only at the probability distribution of payoffs, and impose normative axioms on choices between distributions. ${ }^{2}$ The present paper falls in this category.

The final group of models also looks only at the probability of various consequences. Here, however, an attempt is made to keep normative axioms to a minimum and to see how much flexibility can be maintained while at the same time explaining observed phenomena. The pioneering paper in this line of work is Machina (1982).

This paper introduces an axiom related to, but weaker than, the independence axiom of expected utility theory. We substitute this weaker axiom and obtain a numerical representation for preferences over distributions of payoffs. Naturally, this family of functionals includes the linear functionals of the expected utility family. It also includes the "anticipated utility" representation of Quiggin (1982), Segal (1984) and Yaari (1987). It is disjoint from the quasi-linear family of preferences studied by Dekel (1986), Chew and

1Kahneman and Tversky (1979) and (1984), Loomes and Sugden (1982), Segal (1987). ${ }^{2}$ Chew and MacCrimmon (1979), Chew (1983), Segal (1984), Dekel (1986) and others. 
MacCrimmon (1979), and Gul (1988) except that both contain expected utility as a special case.

There are two reasons for being interested in this axiom and the resulting representation. The first is that although anticipated utility can account for some of the observed violations of expected utility theory, it cannot account for all of them. In particular, the famous phenomenon of Friedman and Savage (1948), in which an individual's risk preferences seemingly depend on his status quo level of wealth, cannot be explained within the anticipated utility framework but can be explained by ours.

Second, and perhaps more importantly, we find the axiom itself intuitively appealing - more so than the necessarily stronger anticipated utility axiom. It is of interest to learn its implications. Part of the reason for the intuitive appeal of this axiom is that it bears some resemblance to psychological concepts of editing. One way in which the comparison between two decision problems can be simplified is to eliminate from consideration some values of payoffs on which the two payoff distributions coincide, and to determine preferences over these distributions by looking at the part of the payoff space on which the conditional distributions differ. Thus the common part of the space is "edited out". We apply this logic when the common part of the space is a half-line: If $F$ and $G$ coincide either above or below some point, then the preference between $F$ and $G$ is determined by their restriction to the complementary half-line, on which they differ. 


\section{Ordinal Independence}

The basic axiom introduced in this paper is called ordinal independence. It applies to spaces of payoffs that are naturally ordered, such as the real numbers. For simplicity, we assume that payoffs are in a bounded interval of real numbers, $X=[\underline{x}, \bar{x}]$. Let the space of probability distributions over $\mathrm{X}$ be denoted $\mathrm{D}$. The elements of $\mathrm{D}$ will be identified with their cumulative distribution functions and will be denoted $F, G, H, \ldots$

Preferences on $\mathrm{D}$ will be described by a binary relation $\succeq$. We assume that $\succeq$ is complete, transitive and continuous.

\section{Complete Weak Order}

The binary relation $\succeq$ on $D$ is a complete weak order: For all $F, G \in D$, either $F \succeq G$ or $G \succeq F$. And if $F \succeq G$ and $G \succeq H$, then $F \succeq H$.

\section{Continuity}

The binary relation is continuous in the weak topology on D.

\section{Monotonicity}

If $F$ (first-order) stochastically dominates $G$, then $F \succeq G$.

To these standard conditions we add the axiom of ordinal independence which can be stated as follows:

\section{Ordinal Independence}

If $F \succeq G$ and $F(x)=G(x)$ for $x \geq \hat{x}$ (resp. $x<\hat{x}$ ), and if $\bar{F}(x)=F(x)$ and $\bar{G}(x)=G(x)$ for all $x<\hat{x}$ (resp. $x \geq \hat{x}$ ) and $\bar{F}(x)=\bar{G}(x)$ for $x \geq \hat{x}(\operatorname{resp} . x<\hat{x})$, then $\bar{F} \succeq \bar{G}$.

This condition is a limited type of independence axiom. Let $\mathrm{H}$ and $\mathrm{H}^{\prime}$ be distributions with support bounded above by $\hat{\mathrm{x}}$ and let $\mathrm{F}$ and $\mathrm{G}$ be distributions with support bounded below by $\hat{\mathbf{x}}$. Then, if the decision maker is indifferent between 
$\propto F+(1-\alpha) H$ and $\propto G+(1-\alpha) H$, he is also indifferent between $\propto F+(1-\propto) H^{\prime}$ and $\alpha \mathrm{G}+(1-\alpha) \mathrm{H}^{\prime}$.

These substitutions preserve indifference if, and in general only if, the support of the conditional distribution being substituted lies entirely above or entirely below the support of the distributions conditional on the complementary event. 


\section{Representation Theorem}

In this section we present the principal representation theorem for preferences satisfying the assumptions discussed in section 2 . We will relate the conclusions of this theorem to both anticipated utility and to expected utility, which are successively special cases.

We begin by stating the theorem and its principal corollary. These state two equivalent closed-form expressions for a numerical index of the preference relation.

\section{Theorem $\underline{3.1}$}

If $\succeq$ satisfies complete weak order, continuity, monotonicity and ordinal independence, then there exists a function $\bar{\phi}: \mathrm{X} \times[0,1] \rightarrow \mathbb{R}$ such that $\bar{\phi}(0, \mathrm{p}) \equiv 0, \bar{\phi}$ is non-decreasing in $\mathrm{x}$, and a measure $\mu$ on $[0,1]$ such that

$$
\mathrm{V}(\mathrm{F}) \equiv \int_{0}^{1} \phi(\mathrm{z}(\mathrm{p}), \mathrm{p}) \mathrm{d} \mu(\mathrm{p})
$$

is a numerical representation of $\succeq$, where

$$
\mathrm{z}(\mathrm{p}) \equiv \inf \{\mathrm{x} \in \mathrm{X} \mid \mathrm{F}(\mathrm{x}) \geq \mathrm{p}\}
$$

Moreover, $\mu$ has a continuous distribution function and $\bar{\phi}$ is continuous on its domain.

\section{Corollary}

Under the hypotheses of theorem 3.1, an alternative representation is

$$
V(F)=\int \bar{h}(x, F(x)) d \nu(x)
$$

where $\bar{h}(\mathrm{x}, 1) \equiv 0$, and $\bar{h}$ is non-increasing in p. Moreover, $\nu$ has continuous 
distribution function and $\bar{h}$ is continuous on its domain.

The meaning of the representations can be seen as follows. We can think of $\bar{\phi}(\mathrm{z}(\mathrm{p}), \mathrm{p})$ as itself being an integral of some function (this will be called $\mu_{2}$ in the proof (see appendix), but let us here denote it by $\zeta(\mathrm{x}, \mathrm{p})$ :

$$
\bar{\phi}(\mathrm{z}(\mathrm{p}), \mathrm{p})=\int_{0}^{z(\mathrm{p})} \zeta(\mathrm{x}, \mathrm{p}) \mathrm{dx}
$$

Thus the numerical utility indicator is an integral of $\zeta(\mathrm{x}, \mathrm{p})$ over the epigraph ${ }^{3}$ of the distribution function as shown below, and with respect to a measure $\mu$ on $[0,1]$.

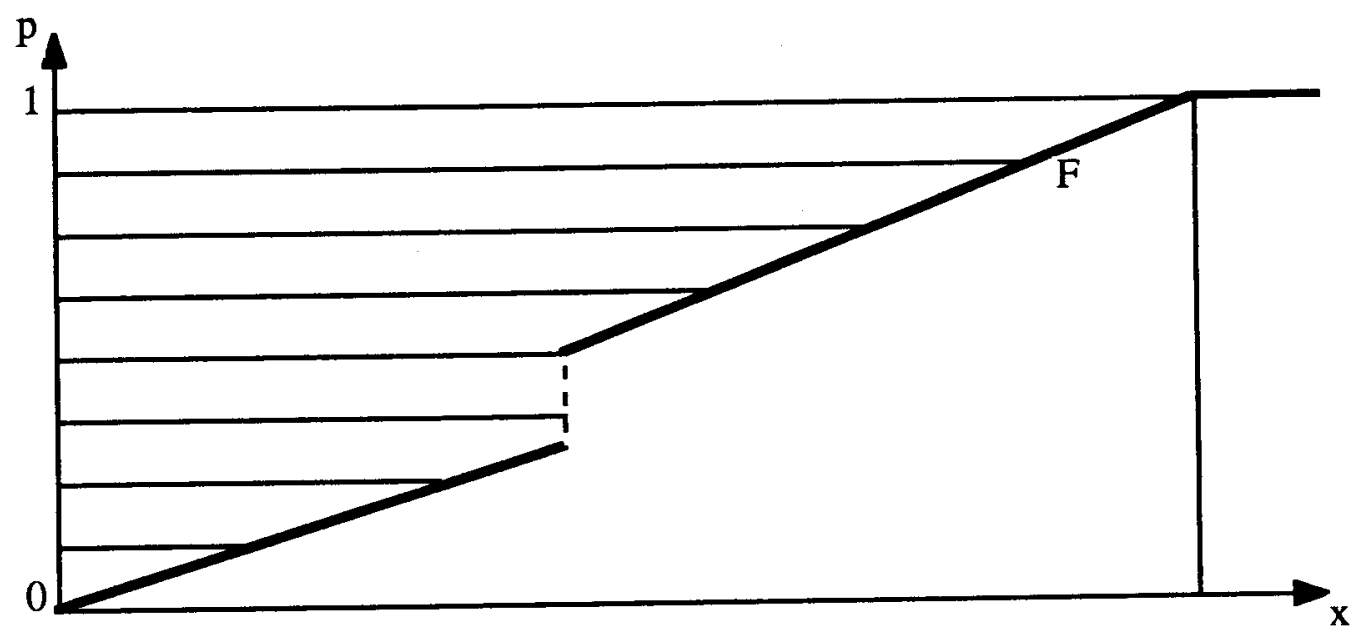

Figure (3.1)

In anticipated utility theory the function $\zeta(\mathrm{x}, \mathrm{p})$ becomes multiplicatively separable: $\zeta(\mathrm{x}, \mathrm{p})=\zeta_{1}(\mathrm{x}) \zeta_{2}(\mathrm{p})$. And, if we incorporate $\zeta_{2}(\mathrm{p})$ into the measure $\mu$, we obtain an expression analogous to that of Segal (1984), Chew, Karni and Safra (1987) and Yaari (1987):

3The idea of using a measure on the epigraph of $F$ as a representation of preferences is due to Segal (1984). See also Chew and Epstein (1987). 


$$
\mathrm{V}(\mathrm{F})=\int \mathrm{u}(\mathrm{x}) \mathrm{d}(\mathrm{g} \circ \mathrm{F}(\mathrm{x}))=\int \mathrm{u}(\mathrm{z}(\mathrm{p})) \operatorname{dg}(\mathrm{p})
$$

where

$$
\begin{aligned}
\operatorname{dg}(\mathrm{p}) & =\zeta_{2}(\mathrm{p}) \mathrm{d} \mu(\mathrm{p}) \\
\mathrm{u}(\mathrm{x}) & =\zeta_{1}(\mathrm{x})
\end{aligned}
$$

Expected utility theory is the further special case in which $\zeta_{2}$ and $\mu$, when so combined, produce a uniform distribution over $[0,1]$. Then, substituting $\mathrm{p}=\mathrm{F}(\mathrm{x})$, one can obtain the usual formula.

$$
\int \zeta_{1}(\mathrm{z}(\mathrm{p})) \mathrm{dp}=\int \zeta_{1}(\mathrm{x}) \mathrm{dx}
$$

The idea in the proof is to show that ordinal independence implies separability in the sense of Gorman (1968), reinterpreted in a certain fashion. The "commodities" that are separable from each other are the levels of payoff at various "percentiles" of the payoff distribution. Thus, a representation of preference will be an additively separable function of the payoffs at these levels. The relative importance of consumption at different percentiles of the payoff distribution is reflected in the measure $\mu$. Intuitively, we are allowing the percentile of the distribution at which any given payoff $\mathrm{x}$ occurs to have two effects. It can affect the value of $\mathrm{x}$, and, independently various percentiles can be more or less important to preferences. 


\section{Representation with Differentiability}

The representation given in section 3 , althought simple, becomes substantially simpler under the following assumption.

Differentiability on Basic Distributions (DBD)

The certainty equivalent, $\mathrm{c}\left(\mathrm{F}_{\alpha, \hat{\mathrm{x}}}\right)$, of the distribution

$$
\begin{aligned}
\mathrm{F}_{\alpha} & =\alpha & & \text { if } \mathrm{x}<\hat{\mathrm{x}} \\
& =1 & & \text { if } \mathrm{x} \geq \hat{\mathrm{x}}
\end{aligned}
$$

is an everywhere differentiable function of $\alpha \in[0,1]$, and of $\mathrm{x}$.

Under this condition, as we will now show, the measure $\mu$ on $[0,1]$ can be shown to be absolutely continuous with respect to Lebesgue measure, having density m. Hence, we can write the representation proven in theorem 3.1 as

$$
V(F)=\int_{0}^{1} \phi(z(p), p) d p
$$

where

$$
\phi(\mathrm{z}(\mathrm{p}), \mathrm{p})=\bar{\phi}(\mathrm{z}(\mathrm{p}), \mathrm{p}) \mathrm{m}(\mathrm{p})
$$

Before proving this assertion, let us consider the following examples in which, because of the failure of (DBD), the measure $\mu$ will not have a density.

Example 1

For any $F$, let $A(F)=\{(z, p) \in X \times[0,1] \mid p \geq F(z)\}$. Let $V(F)$ be given by a measure $\bar{\mu}(\mathrm{A}(\mathrm{F}))$ as follows: The measure $\bar{\mu}$ will be a product measure with factors $\mu_{2}(\mathrm{dx})$ and $\mu(\mathrm{dp})$, where $\mu_{2}$ can be an arbitrary positive measure, absolutely continuous with respect to Lebesgue measure, and $\mu$ has a point mass at $\overline{\mathrm{p}}$.

The preference relation represented by $\mathrm{V}$ will fail to be continuous as one can see by considering a sequence of distributions $\mathrm{F}_{\propto}$ where 


$$
\begin{array}{ll}
\mathrm{F}_{\alpha}(\mathrm{x})=0 & \mathrm{x}<\mathrm{x}_{1} \\
\mathrm{~F}_{\alpha}(\mathrm{x})=\alpha & \mathrm{x}_{1} \leq \mathrm{x}<\overline{\mathrm{x}} \\
\mathrm{F}_{\alpha}(\mathrm{x})=1 & \mathrm{x}=\overline{\mathrm{x}}
\end{array}
$$

Clearly, if $\propto \rightarrow \bar{p}, F_{k} \rightarrow \bar{F}$. But $V\left(F_{\alpha}\right)$ will not converge to $V(\bar{F})$. Thus the preferences will not be continuous.

\section{Example 2}

Modify example 1 so that $\mu$ is a continuous, but not absolutely continuous, measure. For example, $\mu$ can be a probability measure concentrated on the Cantor ternary set (see Royden (1963), ch. 2, problem 42). Then V and the preferences it represents will be continuous. However, preferences will not be differentiable at any $\bar{p}$ in the Cantor ternary set, as

which clearly does not exist.

$$
\frac{\mathrm{dV}\left(\mathrm{F}_{\alpha}\right)}{\mathrm{d} \alpha}=\mu_{2}(\mathrm{X}) \frac{\mathrm{d} \mu[\overline{\mathrm{p}}, 1]}{\mathrm{d} \overline{\mathrm{p}}}
$$

Thus, to avoid problems with differentiability, it will be necessary to avoid measures on $\mathrm{X} \times[0,1]$ which are continuous but not absolutely continuous.

\section{Theorem 4.1}

Let $\succeq$ satisfy the hypotheses of section 3 and Differentiability on Basic Distributions. Then it can be represented by

$$
V(F)=\int_{0}^{1} \phi(z(p), p) d p=\int_{\underline{x}}^{\bar{x}} h(x, F(x)) d x .
$$

Proof: By theorem $3.1 \mathrm{~V}(\mathrm{~F})=\int_{0}^{1} \bar{\phi}(\mathrm{z}(\mathrm{p}), \mathrm{p}) \mathrm{d} \mu(\mathrm{p})$.

Therefore it suffices to show that $\mu$ is absolutely continuous (with respect to Lebesgue measure). By DBD, the derivative of $\mathrm{V}(\mathrm{F})$ at $\mathrm{F}_{\alpha}$ will be 
$\phi(\mathrm{x}, \alpha) \frac{\mathrm{d} \mu(\alpha)}{\mathrm{d} \alpha}$ which exists for all $\alpha$ only if $\mu$ is absolutely continuous. Q.E.D.

Throughout subsequent sections we use the representation (4.1).

It is useful at this point to relate the representation (4.1) to expected utility theory.

If $\succeq$ obeys the independence axiom, and hence can be represented by a linear functional, $\int \mathrm{u}(\mathrm{x}) \mathrm{dF}(\mathrm{x})$, then $\mathrm{h}$ takes the form

$$
\mathrm{h}(\mathrm{x}, \mathrm{F}(\mathrm{x}))=\mathrm{u}^{\prime}(\mathrm{x})(1-\mathrm{F}(\mathrm{x}))
$$

Evaluating (4.1) by integrating (4.2) by parts we have

$$
\int_{\bar{x}}^{\bar{x}} h\left(x, F(x) d x=u(\underline{x})+\int u(x) d F(x)\right.
$$

Thus, we can take $\mathrm{u}(\underline{\mathrm{x}})=0$ by normalization.

As we have pointed, $\phi$ takes the form:

$$
\phi(\mathrm{z}(\mathrm{p}), \mathrm{p})=\mathrm{U}(\mathrm{z}(\mathrm{p}))
$$

It is also fruitful to look at the form of the funtional for particular distributions. Let us consider first a discrete distribution with support $\left(\mathrm{x}_{1}, \ldots, \mathrm{x}_{\mathrm{n}}\right)$ and $\mathrm{p}_{\mathrm{i}}=\operatorname{prob}\left(\mathrm{x}_{\mathrm{i}}\right)$. Define the function:

$$
\psi(x, q, p)=\frac{1}{p} \int_{q-p}^{q} \phi(x, s) d s, \text { where } q \geq p \geq 0
$$

Then we have: 


$$
\begin{aligned}
\mathrm{V}(\mathrm{F}) & =\sum_{\mathrm{i}=1}^{\mathrm{n}} \psi\left(\mathrm{x}_{\mathbf{i}}, \mathrm{F}\left(\mathrm{x}_{\mathrm{i}}\right), \mathrm{p}_{\mathbf{i}}\right) \mathrm{p}_{\mathrm{i}} \\
& =\mathrm{E}_{\mathrm{F}} \psi(\mathrm{x}, \mathrm{F}(\mathrm{x}), \operatorname{prob}(\mathrm{x})) .
\end{aligned}
$$

$\mathrm{V}(\mathrm{F})$ is the expectation of some utility index, where the utility of a given payoff $\mathrm{x}$ depends on its probability of occurrence and its level of cumulative.

Consider now a distribution $\mathrm{F}$ with a density function $\mathrm{f}$. Then, using a simple change of variable:

$$
\mathrm{V}(\mathrm{F})=\int \phi(\mathrm{z}(\mathrm{p}), \mathrm{p}) \mathrm{dp}=\int \phi(\mathrm{x}, \mathrm{F}(\mathrm{x})) \mathrm{f}(\mathrm{x}) \mathrm{dx}
$$

or

$$
\mathrm{V}(\mathrm{F})=\mathrm{E}_{\mathrm{F}} \phi(\mathrm{x}, \mathrm{F}(\mathrm{x}))
$$

Now the utility index depends solely on the level cumulative.

Notice that $\psi(\mathrm{x}, \mathrm{q}, 0)=\phi(\mathrm{x}, \mathrm{F}(\mathrm{x}))$, so that the interpretation given for discrete distributions extends to more general distributions.

Although none of the functionals (4.1) will be Frechet differentiable, except for those satisfying expected utility theory, the weaker hypothesis of Gateaux differentiability (see Chew, Karni and Safra (1987)) can hold and is equivalent to the existence of $\frac{\partial \mathrm{h}(\mathrm{x}, \mathrm{F}(\mathrm{x}))}{\partial \mathrm{F}(\mathrm{x})} \equiv \mathrm{h}_{2}(\mathrm{x}, \mathrm{F}(\mathrm{x}))$.

A functional $\mathrm{V}$ is said to be Gateaux differentiable if for each $\mathrm{F} \in \mathrm{D}$ there exists a linear functional $\mathrm{L}(\cdot, \mathrm{F})$ such that

$$
L\left(F^{\prime}-F, F\right)=\lim _{\epsilon \rightarrow 0} \frac{1}{\epsilon}\left(V\left(\epsilon F^{\prime}+(1-\epsilon) F\right)-V(F)\right)
$$

As Chew, Karni and Safra have shown, the hypothesis of Frechet differentiability used by 
Machina can be weakened to Gateaux differentiability, and properties of the Gateaux derivative can usefully characterize global attitudes towards risk. In this sense the Gateaux derivative is a "local utility function".

The Gateaux derivative of $\mathrm{V}$ at $\mathrm{F}$ is the function (4.3) evaluated for each $\mathrm{x} \in \mathrm{X}$ at the distribution $\mathrm{F}_{\mathrm{x}}^{\prime}$ which is a point mass concentrated at $\mathrm{x}$. Under the hypothesis of Theorem 4.1, and assuming Gateaux differentiability we have that the Gateaux derivative $\mathrm{U}_{\mathrm{F}}(\mathrm{x})$ of $\mathrm{V}$ at $\mathrm{F}$ is,

$$
\mathrm{U}_{\mathrm{F}}(\mathrm{x})=\int_{\underline{\mathrm{x}}}^{\mathrm{x}}-\mathrm{h}_{2}(\mathrm{~s}, \mathrm{~F}(\mathrm{~s})) \mathrm{ds}=\int_{\underline{\mathrm{x}}}^{\mathrm{x}} \phi_{1}(\mathrm{~s}, \mathrm{~F}(\mathrm{~s})) \mathrm{ds}
$$

and

$$
\mathrm{L}\left(\mathrm{F}^{\prime}-\mathrm{F}, \mathrm{F}\right)=\int_{\underline{\mathrm{x}}}^{\overline{\mathrm{x}}} \mathrm{U}_{\mathrm{F}}(\mathrm{x})\left\{\mathrm{dF}^{\prime}(\mathrm{x})-\mathrm{dF}(\mathrm{x})\right\}
$$

We make extensive use of this formula in sections 7 and 8 below. 


\section{5. $\underline{\text { Risk }}$ Aversion}

Throughout the remaining part of the paper, we will restrict ourselves to smooth preferences and assume the following:

\section{$\underline{\text { Smoothness } \text { Condition }}$}

$$
\begin{aligned}
& \phi_{1}=-\mathrm{h}_{2} \text { is continuous and positive } \\
& \phi_{12}=-\mathrm{h}_{22} \text { exists everywhere and is continuous. }
\end{aligned}
$$

One of the main results in Machina's (1982) original paper was that one could use local utility functions to compare the degree of risk aversion of two individuals, extending the analysis of Arrow-Pratt. It is easily seen that the proof of the relevant theorem (theorem 4) uses integrals along lines and requires only that the preference functional $\mathrm{V}$ be Gateaux differentiable (see for example Chew, Karni and Safra (1987)). It follows that the result applies to our preference functional.

A first application is an easy characterization of risk aversion.

\section{Theorem $\underline{5.1}$}

An individual $(\phi, \mathrm{h})$ is risk averse if and only if for all $\mathrm{x}, \mathrm{p}$ :

$$
\begin{aligned}
& \phi_{11}(\mathrm{x}, \mathrm{p})=-\mathrm{h}_{21}(\mathrm{x}, \mathrm{p}) \leq 0 \\
& \phi_{12}(\mathrm{x}, \mathrm{p})=-\mathrm{h}_{22}(\mathrm{x}, \mathrm{p}) \leq 0
\end{aligned}
$$

Proof: Take $\phi^{*}(\mathrm{x}, \mathrm{p})=\mathrm{x}$, the risk neutral preferences in theorem 5.2. An individual is risk averse if $\phi$ is concave in $\mathrm{x}$ and $\mathrm{h}$ convex in $\mathrm{p}$. We can see how the $\phi$-form and the $\mathrm{h}$-form are dual one to another. For any cumulative $\mathrm{F}$ we can interpret its inverse cumulative $z_{F}$ as a cumulative (normalize $\underline{x}$ to 0 and $\bar{x}$ to 1 ). If a cumulative $G$ is a mean-preserving spread of a cumulative $F$, then $z_{F}$ is a mean-preserving spread of ${ }_{\mathrm{G}}^{\mathrm{G}}$. Therefore the concavity of $\phi$ in $\mathrm{x}$ (which corresponds to the concavity of the utility function in expected utility theory) transforms into the convexity of $h$ in $p$.

The characterization of risk aversion is just a special case of a more general result on 
comparative risk aversion.

Definition

A distribution $F$ is said to differ from a distribution $G$ by a simple compensated spread if $V(F)=V(G)$ and if there exists $x^{*}$ such that $F(x) \geq G(x)$ for $\mathrm{x} \leq \mathrm{x}^{*}$ and $\mathrm{F}(\mathrm{x}) \leq \mathrm{G}(\mathrm{x})$ for $\mathrm{x} \geq \mathrm{x}^{*}$.

We will say that an individual $A$ is more risk averse than an individual $B$ if whenever $F$ differs from $G$ by a simple compensated spread from the point of view of $B$, then $\mathrm{A}$ prefers $\mathrm{G}$ to $\mathrm{F}$.

Machina proves the equivalence between several definitions of increasing risk aversion and the fact that for all $\mathrm{F}$, the utility function of $\mathrm{A}$ at $\mathrm{F}$ is a concave transform of the utility function of $\mathrm{B}$ at $\mathrm{F}$. We will interprete this result directly using the functions $\phi$ and $h$.

\section{Theorem $\underline{5.2}$}

An individual $(\phi, \mathrm{h})$ is more risk averse than an individual $\left(\phi^{*}, \mathrm{~h}^{*}\right)$ if and only if for all $\mathrm{x}, \mathrm{p}$ :

$-\frac{\phi_{11}(x, p)}{\phi_{1}(x, p)} \geq-\frac{\phi_{11}^{*}(x, p)}{\phi_{1}^{*}(x, p)} \quad$ and $\quad-\frac{\phi_{12}(x, p)}{\phi_{1}(x, p)} \geq-\frac{\phi_{12}^{*}(x, p)}{\phi_{1}^{*}(x, p)}$

\section{Proof: see appendix}

The extended Arrow-Pratt measure of absolute risk aversion is now composed of two points: $-\frac{\phi_{11}}{\phi_{1}}$ and $-\frac{\phi_{12}}{\phi_{1}}$. It reduces to the usual measure when preferences are linear since then $\phi_{1}(x, p)=u^{\prime}(x)$ and the measure is $\left(-\frac{u^{\prime \prime}(x)}{u^{\prime}(x)}, 0\right)$.

Interpretation in terms of risk premium

The wealth premium

Consider an individual $(\phi, \mathrm{h})$ who is giving the choice between the lotteries over final levels of wealth: 


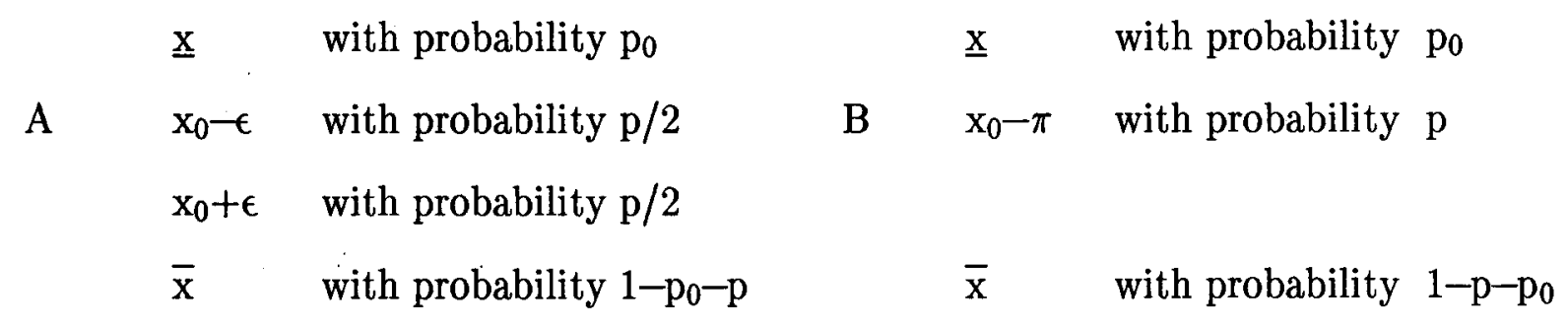

The level of $\pi$ that makes the individual indifferent between the two lotteries is the wealth premium that the individual is willing to pay to avoid the risk $\epsilon$. A straightforward calculus shows that the limit $\tilde{\pi}$ of the premium $\pi$ when p goes to zero is given by:

$$
\frac{1}{2}\left\{\phi\left(\mathrm{x}_{0}-\epsilon, \mathrm{p}_{0}\right)+\phi\left(\mathrm{x}_{0}+\epsilon, \mathrm{p}_{0}\right)\right\}=\phi\left(\mathrm{x}_{0}-\tilde{\pi}, \mathrm{p}_{0}\right)
$$

So $\tilde{\pi}$ is the risk premium associated to the lottery $\left(\epsilon,-\epsilon, \frac{1}{2}, \frac{1}{2}\right)$ when the initial wealth is $\mathrm{x}_{0}$ and the individual maximizes an expected utility with utility function $\phi\left(\mathrm{x}, \mathrm{p}_{0}\right)$. As it is well known, it is approximated by

$$
\tilde{\pi} \simeq-\frac{1}{2} \frac{\phi_{11}\left(\mathrm{x}_{0}, \mathrm{p}_{0}\right)}{\phi_{1}\left(\mathrm{x}_{0}, \mathrm{p}_{0}\right)}\left(\frac{\epsilon^{2}}{2}\right)
$$

When $\mathrm{p}$ is small, $\phi$ is almost linear in $\mathrm{p}$ around $\mathrm{p}_{0}$. Therefore everything is similar to the case of expected utility.

The probability premium

Consider an individual $(\phi, \mathrm{h})$ who is now giving the choice between the lotteries:

$$
\mathrm{x} \quad \text { with probability } \mathrm{p}_{0} \in \quad \mathrm{x}_{0} \text { with probability } \mathrm{p}_{0}-\mathrm{q}
$$
A $\quad x_{0}+\frac{x}{2}$ with probability $2 \epsilon$
B
$\mathrm{x}_{0}+\mathrm{x} \quad$ with probability $1-\mathrm{p}_{0} \in$
$\mathrm{x}_{0}+\mathrm{x}$ with probability $1-\mathrm{p}_{0}+\mathrm{q}$

The level of $\mathrm{q}$ that makes the individual indifferent between the two lotteries is the probability premium that the individual is willing to accept before giving up the extra 
gamble $\epsilon$ (notice that now, when $q=0, A$ is less risky than $B$ ). This example is dual to the previous one. If we reinterpret the inverse cumulative functions as cumulative functions, the two problems are the same except that now $h$ replaces $\phi$. The limit $\tilde{q}$ of the premium $\mathrm{q}$ when $\mathrm{x}$ goes to zero is given by:

$$
\frac{h\left(x_{0}, p_{0}-\epsilon\right)+h\left(x_{0}, p_{0}+\epsilon\right)}{2}=h\left(x_{0}, p_{0}-\tilde{q}\right)
$$

So when $\epsilon$ is small, $\tilde{q}$ can be approximated by

$$
\tilde{\mathrm{q}} \simeq-\frac{1}{2} \frac{\mathrm{h}_{22}\left(\mathrm{x}_{0}, \mathrm{p}_{0}\right)}{\mathrm{h}_{2}\left(\mathrm{x}_{0}, \mathrm{p}_{0}\right)} \frac{\epsilon^{2}}{2}=-\frac{1}{2} \frac{\phi_{12}\left(\mathrm{x}_{0}, \mathrm{p}_{0}\right)}{\phi_{1}\left(\mathrm{x}_{0}, \mathrm{p}_{0}\right)} \frac{\epsilon^{2}}{2}
$$

Notice that under expected utility, $\tilde{\mathrm{q}}$ is exactly zero. When $\mathrm{x}$ is close to 0 , the utility function is almost linear and the agent is risk neutral. With non-linear preferences, the marginal utility of wealth becomes almost constant in the relevant range, but there is another dimension to risk aversion. Preferences can be represented by Yaari's dual preferences. 


\section{The Allais Paradox and the Common Ratio Effect}

The Allais paradox and other related observations have been extensively examined in the existing literature. We refer the reader to Kahneman-Tversky (1979) and MacCrimmon-Larsson (1979) for detailed exposition and discussion. We will restrict most of our discussion to the case of three outcomes distributions $\left(\mathrm{x}_{1}, \mathrm{x}_{2}, \mathrm{x}_{3}, \mathrm{p}_{1}, \mathrm{p}_{2}, \mathrm{p}_{3}\right)$ with $\mathrm{x}_{1}<\mathrm{x}_{2}<\mathrm{x}_{3}$. There is a very convenient graphical representation of such a distribution introduced by Machina: for given outcomes $x_{1}<x_{2}<x_{3}$, we can represent a distribution in the plane by using $\mathrm{p}_{1}$ and $\mathrm{p}_{3}$, the probabilities of the low and the large outcomes. Diagram (6.1) illustrates the common ratio effect.

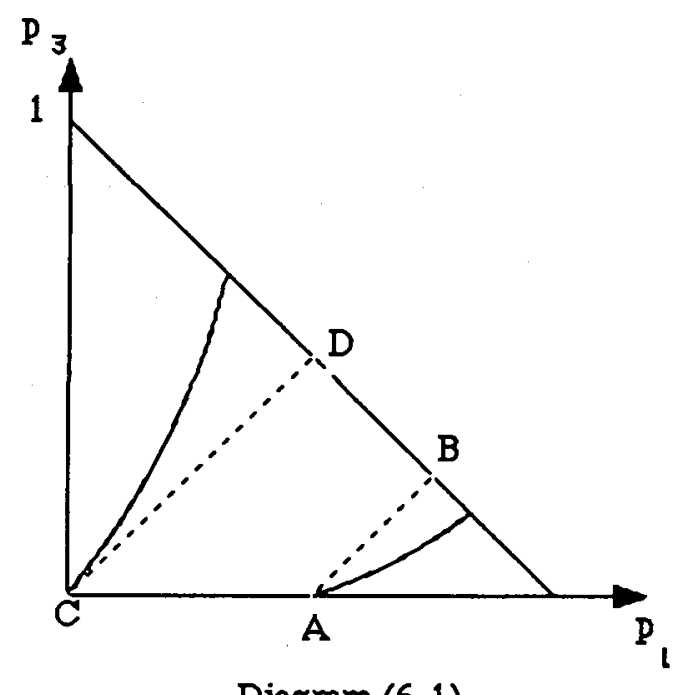

Diagram (6.1).

The sure outcome C is preferred to the lottery D. A and B are obtained from C and D by mixing the bad outcome with probability q. In many observations $B$ is preferred to A, contradicting the prediction of expected utility theory. Notice that under expected utility the isopreference curves are parallel straight lines. Similarly, diagram (6.2) illustrates the Allais paradox. 


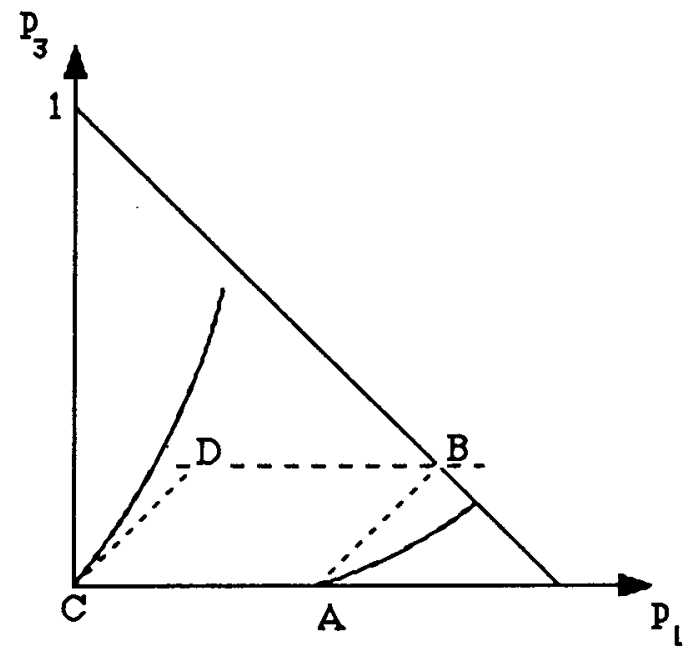

Diagram (6.2).

Now $\mathrm{A}$ and $\mathrm{B}$ are obtained from $\mathrm{C}$ and $\mathrm{D}$ by transferring a probability $\mathrm{q}$ from the medium outcome $x_{2}$ to the low outcome $x_{1}$. As before, an expected utility maximizer who prefers $\mathrm{C}$ to $\mathrm{D}$ must prefer $\mathrm{A}$ to $\mathrm{B}$.

Machina (1982) proposes to generalize both paradoxes under the following behavioral assumption:

Generalized Common Ratio Effect $(\mathrm{GCRE})$ : Let $\mathrm{F}_{\mathrm{A}}, \mathrm{F}_{\mathrm{B}}, \mathrm{F}_{\mathrm{C}}, \mathrm{F}_{\mathrm{D}} \in \mathrm{D}$ be such that $\mathrm{F}_{\mathrm{C}}$ and $\mathrm{F}_{\mathrm{D}}$ respectively stochastically dominate $\mathrm{F}_{\mathrm{A}}$ and $\mathrm{F}_{\mathrm{B}}$, and $\mathrm{F}_{\mathrm{D}}-\mathrm{F}_{\mathrm{C}}=\lambda\left(\mathrm{F}_{\mathrm{B}}-\mathrm{F}_{\mathrm{A}}\right)$ for some $\lambda>0$. Then, if $\mathrm{F}_{\mathrm{B}}$ differs from $\mathrm{F}_{\mathrm{A}}$ by a simple compensated spread, $\mathrm{V}\left(\mathrm{F}_{\mathrm{D}}\right) \leq \mathrm{V}\left(\mathrm{F}_{\mathrm{C}}\right)$. Similarily, if $\mathrm{F}_{\mathrm{D}}$ differs from $\mathrm{F}_{\mathrm{C}}$ by a simple compensated spread, then $\mathrm{V}\left(\mathrm{F}_{\mathrm{B}}\right) \geq \mathrm{V}\left(\mathrm{F}_{\mathrm{A}}\right)$.

When the distributions have a support composed only of three outcomes $\mathrm{x}_{1}<\mathrm{x}_{2}<\mathrm{x}_{3}$, the GCRE has the following interpretation. 


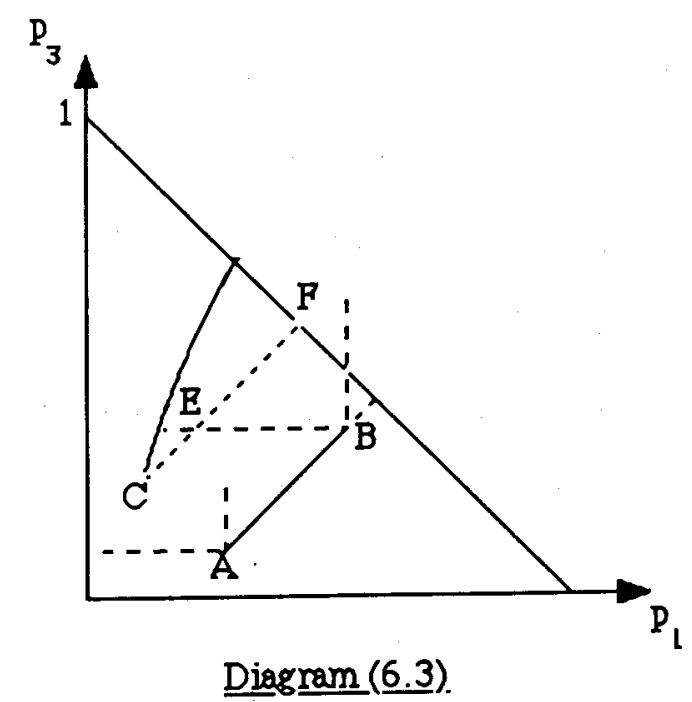

A distribution stochastically dominates another distribution if it lies above and on the left. If we choose $\mathrm{A}, \mathrm{B}, \mathrm{C}$ as shown and $\mathrm{A} \sim \mathrm{B}$, then $\mathrm{C}$ must be preferred to any distribution on the segment $[E, F]$. By choosing $B$ close to $A$, we see that it implies that the slope of the isopreference curve at $\mathrm{C}$ be greater than the slope of the isopreference curve at $A$. The slope of the isopreference curve at some point $\left(p_{1}, p_{3}\right)$ is given by

$$
\left.\frac{d p_{3}}{d p_{1}}\right|_{V}=\frac{\phi\left(x_{2}, p_{1}\right)-\phi\left(x_{1}, p_{1}\right)}{\phi\left(x_{3}, 1-p_{3}\right)-\phi\left(x_{2}, 1-p_{3}\right)}
$$

The GCRE implies that this ratio be non-increasing with $\mathrm{p}_{1}$ and non-decreasing with $\mathrm{p}_{3}$

\section{Theorem 6.1}

An individual $(\phi, \mathrm{h})$ verifies the GCRE if and only if she is an expected utility maximizer.

Proof: Choose any $x_{1}<x_{2}<x_{3}<x_{4}$, then $\frac{\phi\left(x_{2}, p_{1}\right)-\phi\left(x_{1}, p_{1}\right)}{\phi\left(x_{3}, 1-p\right)-\phi\left(x_{2}, 1-p\right)}$ is non-decreasing with $\mathrm{p}$ and $\frac{\phi\left(\mathrm{x}_{3}, \mathrm{p}\right)-\phi\left(\mathrm{x}_{2}, \mathrm{p}\right)}{\phi\left(\mathrm{x}_{4}, 1-\mathrm{p}_{3}\right)-\phi\left(\mathrm{x}_{3}, 1-\mathrm{p}_{3}\right)}$ non-increasing with $\mathrm{p}$. This is only possible if $\phi\left(\mathrm{x}_{3}, \mathrm{p}\right)-\phi\left(\mathrm{x}_{2}, \mathrm{p}\right)$ is independent of $\mathrm{p}$, or $\phi_{1}(\mathrm{x}, \mathrm{p})=\mathrm{u}^{\prime}(\mathrm{x}) . \quad \mathrm{QED}$ 
The theorem generalizes the same result obtained by Segal (1984) for anticipated utility, it shows that this is not linked to the multiplicative separability. Segal then proposed a weaker behavioral assumption inspired by the Allais paradox:

Generalized Allais Paradox $\underline{\text { (GAP): }}$ Let $\mathrm{F}_{\mathrm{A}}, \mathrm{F}_{\mathrm{B}}, \mathrm{F}_{\mathrm{C}}, \mathrm{F}_{\mathrm{D}}$ be such that $\mathrm{F}_{\mathrm{C}}$ and $\mathrm{F}_{\mathrm{D}}$ respectively stochastically dominate $\mathrm{F}_{\mathrm{A}}$ and $\mathrm{F}_{\mathrm{B}}$, and $\mathrm{F}_{\mathrm{D}}-\mathrm{F}_{\mathrm{C}}=\mathrm{F}_{\mathrm{B}}-\mathrm{F}_{\mathrm{A}}$. Let $\mathrm{V}\left(\mathrm{F}_{\mathrm{A}}\right)=\mathrm{V}\left(\mathrm{F}_{\mathrm{B}}\right)$ and $\mathrm{x}^{*}$ be such that for $\mathrm{x} \geq \mathrm{x}^{*}, \mathrm{~F}_{\mathrm{A}}(\mathrm{x}) \geq \mathrm{F}_{\mathrm{B}}(\mathrm{x})$ and for $\mathrm{x} \leq \mathrm{x}^{*}$, $\mathrm{F}_{\mathrm{A}}(\mathrm{x}) \leq \mathrm{F}_{\mathrm{B}}(\mathrm{x})$. If for $\mathrm{x} \geq \mathrm{x}^{*}, \mathrm{~F}_{\mathrm{C}}(\mathrm{x})=\mathrm{F}_{\mathrm{A}}(\mathrm{x})$, then $\mathrm{V}\left(\mathrm{F}_{\mathrm{C}}\right) \geq \mathrm{V}\left(\mathrm{F}_{\mathrm{D}}\right)$.

In this version $\mathrm{C}$ and $\mathrm{D}$ are obtained by shifting in the same amount probabilities from low to medium outcomes, as in the Allais paradox. In the case of three outcomes, it means that $\mathrm{A}$ and $\mathrm{C}$ are on the same horizontal line, and so are $\mathrm{B}$ and $\mathrm{D}$.

\section{Theorem $\underline{6.2}$}

The preferences $(\phi, h)$ verify the GAP if and only if for all $x, p$ : $\phi_{12}(\mathrm{x}, \mathrm{p})=-\mathrm{h}_{22}(\mathrm{x}, \mathrm{p}) \leq 0$.

Proof: See appendix.

The result is interesting because it shows that the type of behavior characterizing the Allais paradox is not only compatible with but is implied by risk aversion. ${ }^{4}$ It suggests that the best candidates to explain some risk-loving behavior while staying consistent with experimental observations are preferences with $\mathrm{h}$ convex in $\mathrm{p}$ but $\phi$ not concave in $\mathrm{x}$.

Remark: The GAP doesn't imply the "common ratio effect". The reason is that if $\phi_{12} \leq 0$, the isopreference curves are concave so that the GAP doesn't prevent the situation depicted on diagram (6.4).

4In the case of a multiplicatively separable form $\phi_{1}(x, p)=u^{\prime}(x) f^{\prime}(1-p)$ the condition reduces to $\mathrm{f}$ convex as found by Segal (1984). 


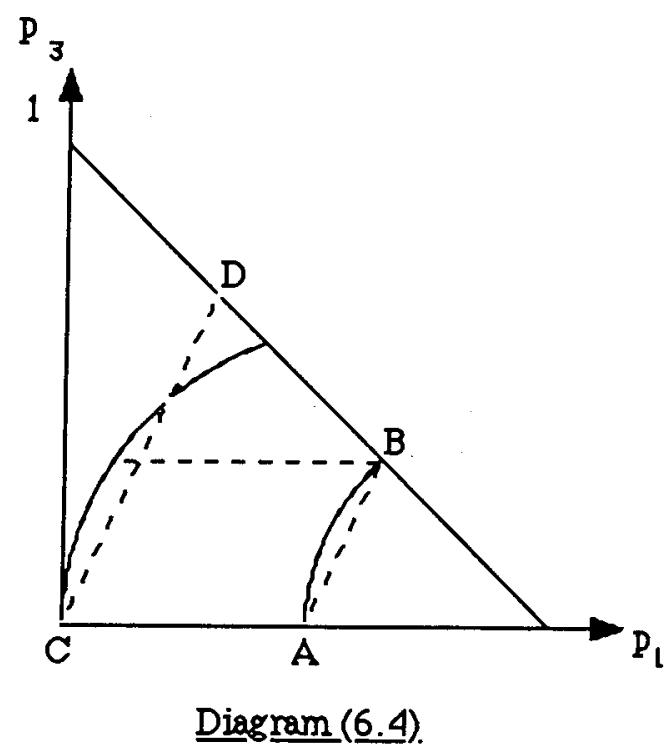

However it is clear that they are not contradictory. 


\section{The Friedman-Savage Hypothesis and the Boundedness of Preferences}

In their seminal article Friedman-Savage (1948), pointed out that many individuals were simultaneously purchasing lottery tickets and insurance. They proposed a von Neumann-Morgenstein utility function concave for low outcomes (and hence risk averse) and convex for large outcomes (risk loving). There were several difficulties with this utility representation. First the utility function was unbounded, therefore inducing unbounded preferences and subject to the "St. Petersburg Paradox". In addition the

willingness to pay for $\frac{1}{\mathrm{k}}$ chance of winning $\$ \mathrm{k} \epsilon$ was increasing with $\mathrm{k}$. This led them to add a terminal concave part at very large outcomes. Finally, it could not explain why people purchase lottery tickets and insurance regardless of their initial wealth. These points are discussed with great details by Machina (1982). As was pointed by Machina, when the preference functional is non-linear in the distributions, preferences may be bounded even though the local utility functions are unbounded. This could explain at the same time the observed gambling behaviors and their relative invariance to the initial wealth since the inflexion point of the local utility function would depend on the initial wealth. Machina's analysis relies on Frechet differentiability and therefore cannot be applied directly to our preference relation. The reason is that when $\mathrm{V}$ is Frechet differentiable, the derivative of $\mathrm{V}$ at some point characterizes the local behavior of $\mathrm{V}$ in a precise sense, however, this is not true if $\mathrm{V}$ is Gateaux differentiable. In the latter case, we cannot uniformly approximate $\mathrm{V}$ by its derivative in some neighborhood.

Let us first mention that the boundedness of preferences guarantees that the agent will not purchase a lottery ticket with too high a prize.

\section{Theorem 7.1}

Suppose that $V$ is bounded, then for all $w>0$ and $\epsilon>0$, the sure outcome $w$ is preferred to the lottery $\left(w-\epsilon, w+\frac{1-p}{p} \epsilon, 1-p, p\right)$ for $p$ small enough. Proof: see appendix.

The theorem tells us that a decision maker will not purchase a fair gamble offering 
$\mathrm{k} \epsilon$ with probability $1 / \mathrm{k}$ if $\mathrm{k}$ is too large.

We now turn to the problem of the unbounded utility functions. It appears quickly that the non-separability of the function $\phi$ and $\mathrm{h}$ is crucial.

\section{Theorem $\underline{7.2}$}

If $\phi$ is separable, i.e. $\phi(x, p)=u(x) g(p)$, and $V(\cdot)$ is bounded, then the local utility function at any distribution $\mathrm{F}$ is bounded.

Proof: Let $\mathrm{G}_{\mathrm{W}}$ be the cumulative distribution of a point mass at $\mathrm{W}$,

$$
\begin{aligned}
& \mathrm{V}\left(G_{W}\right)=u(w) \int_{0}^{1} g(p) d p, \text { so } u(\cdot) \text { is bounded. } \\
& U_{F}(x)=\int_{0}^{x} u^{\prime}(s) g(F(s)) d s<\sup g \text { sup } u \quad \text { QED }
\end{aligned}
$$

When $\phi$ is not separable, we can easily construct preferences that are bounded with unbounded utility functions, using the following lemma.

\section{Lemma 7.1}

If the function $p \in] 0,1\left[\rightarrow \sup _{x} \phi(x, p)\right.$ is $L^{1}$, then $V(\cdot)$ is bounded.

Proof: $V(F)=\int_{0}^{1} \phi(z(p), p) d p<\int_{0}^{1} \sup \{\phi(x, p)\} d p$

So to exhibit some bounded preference functional $\mathrm{V}$ with an unbounded local utility function $U_{F}$ at all distribution $F$, we choose $\phi$ verifying the condition of lemma (7.1) and such that $\phi(\mathrm{x}, 1)$ is unbounded. If we choose $\phi(\mathrm{x}, 0)$ to be concave and $\phi(\mathrm{x}, 1)$ to be convex, the utility functions will have the desired concave-convex shape (see figure (7.1) and (7.2)).

Note that at the same time we solve the problem of the relative invariance of gambling behavior to initial wealth, since the inflexion point (or region) of the utility function will change with the initial distribution. An appealing property is that for a non-random wealth $\mathrm{w}$, the inflexion point is exactly at $\mathrm{w}$. 


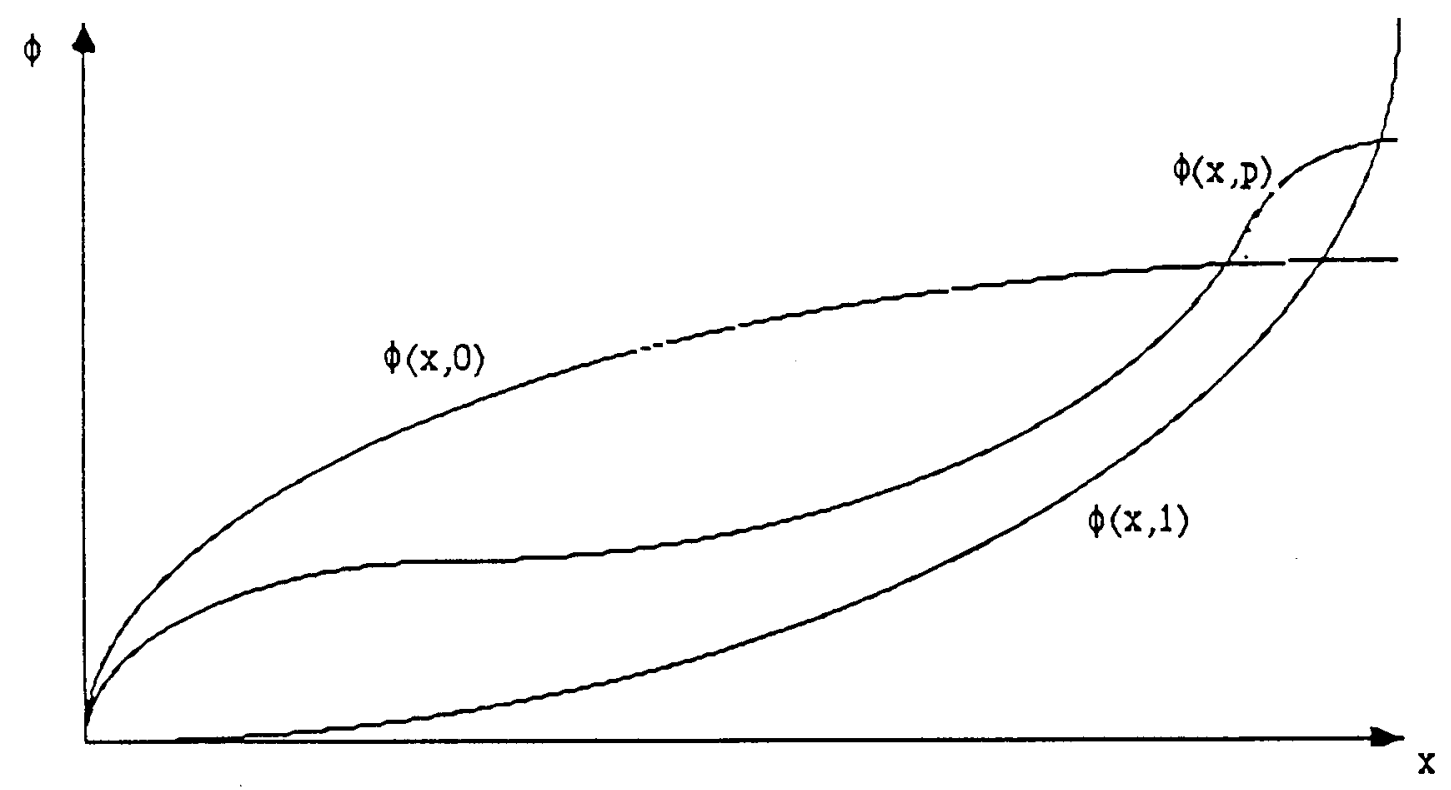

Pigure (7.1).

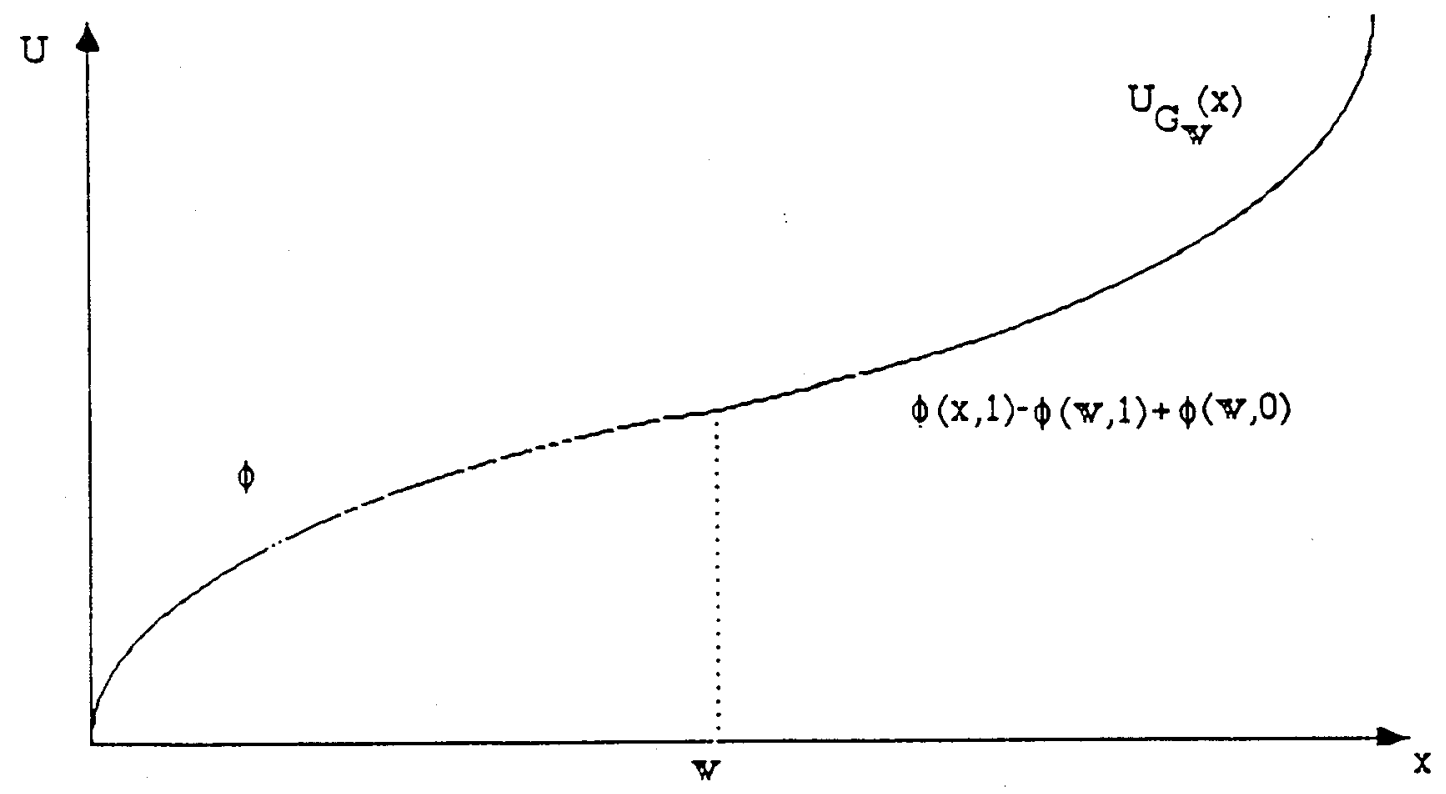

Figure (7.2). 
As we pointed above, the derivative of $\mathrm{V}$ at $\mathrm{F}$ doesn't characterize completely the local behavior of $\mathrm{V}$. When talking about lottery or insurance, we do not consider unidirectional pertubations of the initial wealth, so that a decision maker may not want to purchase a lottery ticket or an insurance contract even though the local utility function has the right shape. The strategy we adopted is to characterize the conditions under which she would purchase a lottery involving a fixed gain or an insurance against a fixed loss if the probability of the event considered is small enough, in the spirit of the local analysis.

Lemma (7.2)

An individual with initial distribution $\mathrm{F}$ will accept the lottery $\left(\epsilon,-\frac{p}{1-p} \epsilon, p, 1-p\right)$ when $p$ is small if

$$
\mathrm{E}_{\mathrm{F}}\left\{\frac{\mathrm{U}_{\mathrm{F}}(\mathrm{x}+\epsilon)-\mathrm{U}_{\mathrm{F}}(\mathrm{x})}{\epsilon}\right\}>f^{1} \phi_{1}(\mathrm{z}(\mathrm{p}), \mathrm{p}) \mathrm{dp}
$$

and only if the weak inequality holds.

Proof: see appendix.

For the case of insurance, the initial distribution must include the loss but the result is similar.

\section{Lemma (7.3)}

An individual with an initial distribution $\mathrm{G}(\mathrm{x})=\mathrm{pF}(\mathrm{x}+\epsilon)+(1-\mathrm{p}) \mathrm{F}(\mathrm{x})$, i.e. wealth $w$ with distribution $F(w)$ plus an additional $p$ chance of loosing $\epsilon$ independently of $w$, will insure against the loss $\epsilon$ when $p$ is small enough if

$$
E_{F}\left\{\frac{\mathrm{U}_{\mathrm{F}}(\mathrm{x})-\mathrm{U}_{\mathrm{F}}(\mathrm{x}-\epsilon)}{\epsilon}\right\}>\int_{0}^{1} \phi_{1}(\mathrm{z}(\mathrm{p}), \mathrm{p}) \mathrm{dp},
$$

and only if the weak inequality holds.

The conditions when $\mathrm{V}$ is Frechet differentiable are the same except that 
$\int_{0}^{1} \phi_{1}(\mathrm{z}(\mathrm{p}), \mathrm{p}) \mathrm{dp}$ is to be replaced by $\mathrm{E}_{\mathrm{F}} \mathrm{U}_{\mathrm{F}}^{\prime}(\mathrm{x})$. If we assume that $\phi_{12}(\mathrm{x}, \mathrm{p}) \leq 0$, then $\int_{0}^{1} \phi_{1}(\mathrm{z}(\mathrm{p}), \mathrm{p}) \mathrm{dp} \geq \int_{0}^{1} \phi_{1}(\mathrm{x}, \mathrm{F}(\mathrm{x})) \mathrm{dF}(\mathrm{x})=\mathrm{E}_{\mathrm{F}} \mathrm{U}_{\mathrm{F}}^{\prime}(\mathrm{x})$, so that the conditions (7.a) and (7.b) are stronger. However when the distribution $\mathrm{F}$ has no point-mass, $\int_{0}^{1} \phi_{1}(\mathrm{z}(\mathrm{p}), \mathrm{p}) \mathrm{dp}=\int_{0}^{1} \phi_{1}(\mathrm{x}, \mathrm{F}(\mathrm{x})) \mathrm{dF}(\mathrm{x})$. Therefore it is natural to impose as a first requirement that the local utility function at a smooth distribution have a concave-convex shape. If we want preferences to be bounded, this rules out separable forms $\phi(x, p)=u(x) g(p)$.

There is a more fundamental reason to exclude separable forms. As was done by Friedman and Savage, a separable form could be reconciled with bounded preferences by adding a terminal concave section to the utility functions. But a separable form cannot explain the invariance of gambling behavior to initial wealth. The local utility function for a fixed initial wealth $w$ when $\phi(x, p)=u(x) g(p)$ is given by:

$$
\begin{aligned}
\mathrm{U}_{\mathrm{G}_{\mathrm{W}}}(\mathrm{x}) & =\mathrm{u}(\mathrm{x}) \mathrm{g}(0) & & \text { if } \mathrm{x} \leq \mathrm{w} \\
& =\mathrm{u}(\mathrm{x}) \mathrm{g}(1)-\mathrm{u}(\mathrm{w})\{\mathrm{g}(1)-\mathrm{g}(0)\} & & \text { if } \mathrm{x} \geq \mathrm{w}
\end{aligned}
$$

We see that the shape of the utility function at some level $\mathrm{x}$ is independent of $\mathrm{w}$. It is impossible that the utility be concave-convex with an inflexion point close to $\mathrm{w}$ for all $\mathrm{G}_{\mathrm{W}}$, since the inflexion point must be independent of $\mathrm{w}$.

Remark: If $\phi_{12}(\mathrm{w}, \mathrm{p}) \leq 0$ and $\phi(\mathrm{x}, 0)$ is concave, when the initial distribution is $\mathrm{G}_{\mathrm{w}},(7 . \mathrm{b})$ is verifies for all $\epsilon \leq \mathrm{w}$, while (7.a) is not verified for $\epsilon$ small. This is consistent with the existence of lotteries with substantial prizes only.

Using lemmas (7.1) and (7.2), we see that to build an example of bounded preferences compatible with the simultaneous purchase of lottery tickets and insurance, one 
can do the construction illustrated on figures (7.1) and (7.2) and choose $\phi(x, 1)$ such that $\lim _{x \rightarrow+\infty} \phi_{1}(x, 1)=+\infty$. Then the individual will purchase a lottery $(\epsilon, p)$ when $\epsilon$ is large and $p$ is small enough. This doesn't contradict the theorem (7.1) because the probability $\mathrm{p}$ has to be chosen after $\epsilon$. In theorem (7.1) we fix the premium and increase the prize, while now we fix the prize and decrease the premium. The next section will give specific examples. 


\section{Integrated Solutions.}

We want now to determine whether the theory enables us to reconcile the behaviors discussed in section 6 and 7 with the same preference functional. More precisely, can we find $\phi$ and $h$ such that preferences are bounded, the GAP is verified and, at least for all $\mathrm{G}_{\mathrm{w}}$, the relations (7.a) and (7.b) are verified for some $\epsilon>0$ ? It turns out that if we do not restrict the levels of wealth considered, the search is hopeless. We show below that the GAP and the purchase of some lottery tickets at all level of wealth (as we defined it) are incompatible with bounded preferences.

\section{Theorem 8.1}

Suppose that for all $\mathrm{x}, \mathrm{p}, \phi_{12}(\mathrm{x}, \mathrm{p})<0$ and that for all distributions $\mathrm{G}_{\mathrm{w}}$ there exists $\epsilon>0$ such that (7.a) is verified, then preferences are unbounded. Proof: see appendix.

The intuition behind the results is that if $\phi_{12}(x, p)<0$, the slope of $\phi(., p)$ decreases with $\mathrm{p}$ so that when $\phi(., 1)$ is unbounded, so will be $\phi(., p)$. But if $\phi(., p)$ is unbounded for all $\mathrm{p}$, preferences must be unbounded.

The result is not so disturbing because wishing to reconcile everything at all levels of wealth appears a little excessive. After all we are talking about the initial wealth of the individual, and initial wealth is bounded. We will show in the following examples that we can still go very far in the search of an integrated solution. The problem comes from the behavior when the initial wealth is very large. If we assume that either the GAP or relation (7.a) is verified only for bounded levels of initial wealth, the other requirements can be verified for all level of wealth.

Examples

$\underline{\text { Example } \underline{0}}$

Suppose that $\phi(x, p)=x+(1-2 \sqrt{p}) \frac{x}{1+x}$ 
Then $\phi_{1}(\mathrm{x}, \mathrm{p})=1+\frac{(1-2 \sqrt{\mathrm{p}})}{(1+\mathrm{x})^{2}}>0$

$$
\phi_{12}(x, p)=-\frac{1}{\sqrt{p}(1+x)^{2}}<0
$$

$\phi(., p)$ is concave for $\mathrm{p}<\frac{1}{4}$, convex for $\mathrm{p}>\frac{1}{4}$

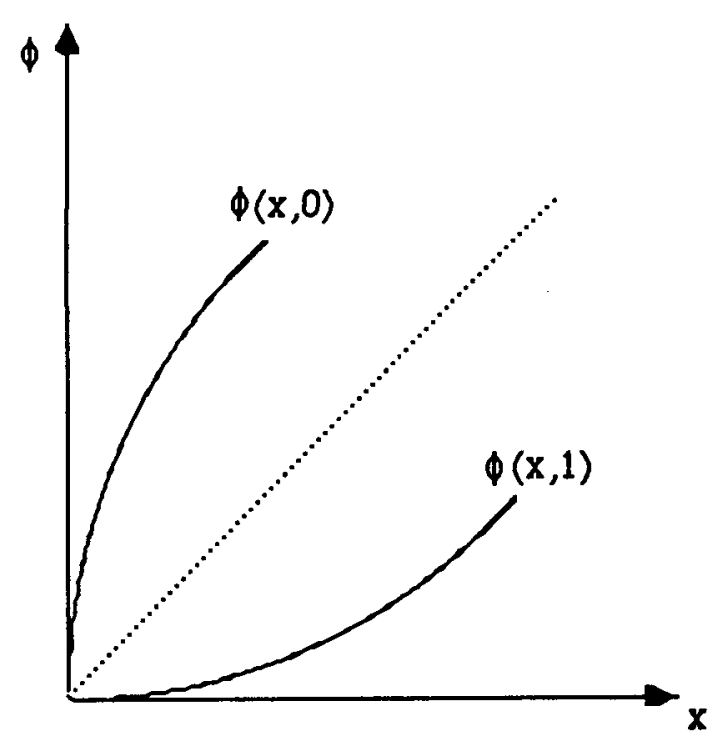

Figure (․1.1).

For $F=G_{w}, \int_{0}^{1} \phi_{1}(w, p) d p=1-\frac{1}{3} \frac{1}{(1+w)^{2}}$, while

$\frac{\mathrm{U}_{\mathrm{G}_{w}}(w+\epsilon)-\mathrm{U}_{\mathrm{G}_{\mathrm{w}}}(w)}{\epsilon}=1+\frac{1}{\epsilon}\left[\frac{\mathrm{w}}{1+w}-\frac{w+\epsilon}{1+w+\epsilon}\right]$,

$\frac{\mathrm{U}_{\mathrm{G}_{\mathrm{w}}}(w-\epsilon)-\mathrm{U}_{\mathrm{G}_{\mathrm{w}}}(\mathrm{w})}{\epsilon}=1+\frac{1}{\epsilon}\left[\frac{\mathrm{w}}{1+\mathrm{w}}-\frac{w-\epsilon}{1+w-\epsilon}\right]$.

Therefore (7.a) is verified for $\epsilon>(1+w) 2$, while (7.b) is verified for all $\epsilon<w$. One appealing aspect is that the purchase of insurance appears to be more general than the purchase of lottery tickets. However preferences are unbounded: 
$V\left(G_{w}\right)=\int_{0}^{1}\left\{w+(1-2 \sqrt{p}) \frac{w}{1+w}\right\} d p=w-\frac{1}{3} \frac{w}{1+w} \frac{}{w \rightarrow+\infty}+\infty$

\section{Example 1}

Choose $\mathrm{k}$ large enough:

$$
\begin{aligned}
\phi(x, p) & =x+(1-2 \sqrt{p}) \frac{x}{1+x} & & \text { if } x \leq k \\
& =\phi(k, p)+\phi_{1}(k, p) \frac{x-k}{1+x-k} & & \text { if } x \geq k
\end{aligned}
$$

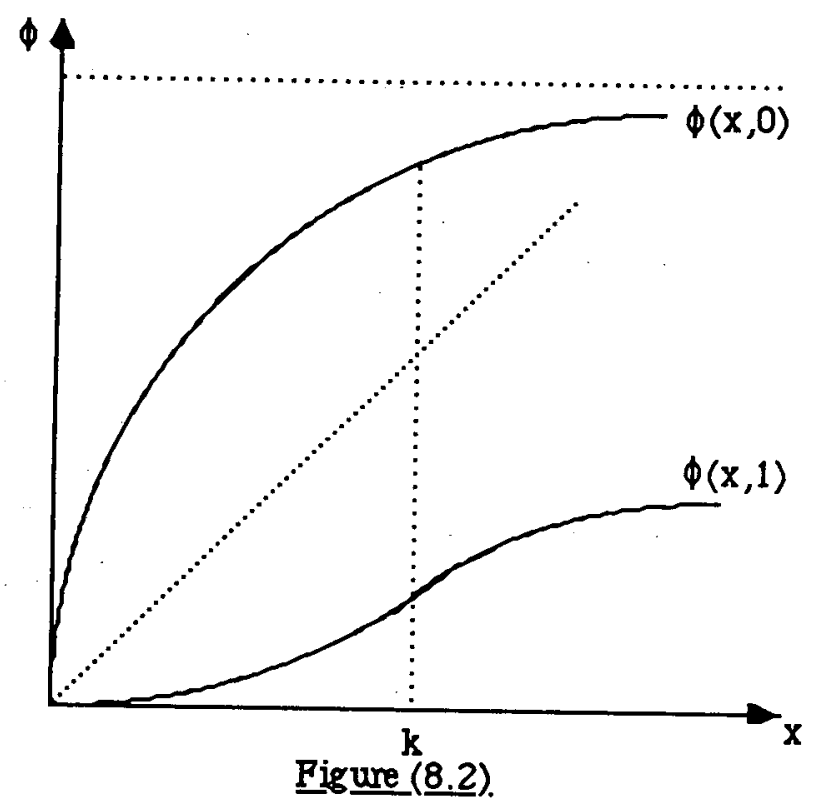

Now the preferences are bounded since

$\phi(\mathrm{x}, \mathrm{p})<\phi(\mathrm{k}, \mathrm{p})+\phi_{1}(\mathrm{k}, \mathrm{p})<\mathrm{k}+\frac{\mathrm{k}}{1+\mathrm{k}}+1+\frac{1}{(1+\mathrm{k})^{2}}$.

$\phi_{1}$ is defined everywhere and continuous:

$\phi_{1}(x, p)=1+\frac{1-2 \sqrt{p}}{(1+x)^{2}}$ if $\quad x \leq k \quad \phi_{1}(x, p)=\phi_{1}(k, p) \frac{1}{(1+x-k)^{2}}$ if $x \geq k$ 
$\phi_{12}(\mathrm{x}, \mathrm{p})$ is defined everywhere and $\phi_{12}(\mathrm{x}, \mathrm{p})<0$ :

$$
\begin{aligned}
\phi_{12}(\mathrm{x}, \mathrm{p}) & =-\frac{1}{\sqrt{\mathrm{p}(1+\mathrm{x})^{2}}} & & \text { if } \mathrm{x} \leq \mathrm{k} \\
& =-\frac{1}{\sqrt{\mathrm{p}}(1+\mathrm{k})^{2}(1+\mathrm{x}-\mathrm{k})^{2}} & & \text { if } \mathrm{x} \geq \mathrm{k}
\end{aligned}
$$

So the GAP is verified. Provided that $\mathrm{w}<\frac{1}{3}(\mathrm{k}-2)$, an individual with initial wealth $\mathrm{w}$ will purchase some lottery tickets and insure all small risk ((7.a) is verified for some $\epsilon$ and (7.b) for all $\epsilon<w)$.

\section{Example 2}

Define $x(p)=\frac{k}{\sqrt{p(1-p)}}, k$ large.

$$
\begin{aligned}
\phi(x, p) & =x+(1-2 \sqrt{p}) \frac{x}{1+x} & & \text { if } x \leq x(p) \\
& =\phi(x(p), p)+\phi_{1}(x(p), p) \frac{x-x(p)}{1+x-x(p)} & & \text { if } x \geq x(p) .
\end{aligned}
$$

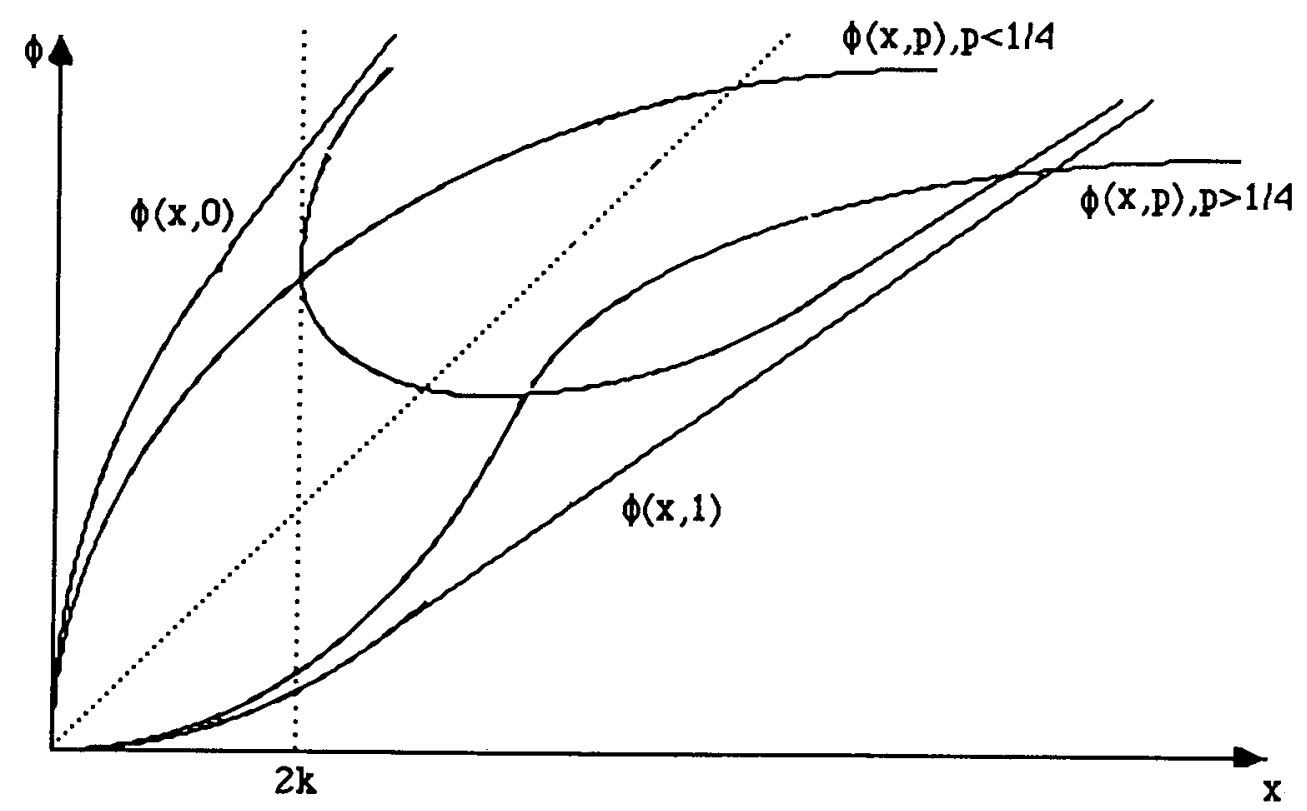


As in example 1, $\phi_{1}$ is defined, continuous and positive everywhere. As long as $\mathrm{x}<\mathrm{x}(\mathrm{p}), \phi_{12}(\mathrm{x}, \mathrm{p})$ is defined and negative so that the GAP is verified at least for distributions with upper bound less than $2 \mathrm{k}$.

For a fixed wealth w, the utility is:

$$
\begin{aligned}
\mathrm{U}_{\mathrm{G}_{\mathrm{W}}}(\mathrm{x}) & =\mathrm{x}+\frac{\mathrm{x}}{1+\mathrm{x}} & & \text { if } \mathrm{x} \leq \mathrm{w} \\
& =\mathrm{x}-\frac{\mathrm{x}}{1+\mathrm{x}}+2 \frac{\mathrm{w}}{1+\mathrm{w}} & & \text { if } \mathrm{x} \geq \mathrm{w} .
\end{aligned}
$$

The utility function at $\mathrm{G}_{\mathrm{w}}$ is the same as in example 0 (only $\phi(., 0)$ and $\phi(., 1)$ matter). Notice that ${ }^{5} \phi_{1}(x, p) \leq 1+\frac{1-2 \sqrt{p}}{(1+x)}$. Therefore the results of example 0 hold and an individual with initial wealth $\mathrm{w}$ will purchase some lottery tickets and insure all small risks.

${ }^{5}$ For all $\alpha \in[-1,1], x>k, 1+\frac{\alpha}{(1+x)^{2}}>\left[1+\frac{\alpha}{(1+k)^{2}}\right] \frac{1}{(1+x-k)^{2}}$. 


\section{Appendix}

\section{Proof of Theorem $\underline{3.1}$}

We begin by considering the set of all distributions with equally unlikely outcomes, $\mathrm{D}^{\mathrm{E}}$, and, for each $\mathrm{n}$, the subset $\mathrm{D}_{\mathrm{n}}^{\mathrm{E}} \mathrm{C} \mathrm{D}^{\mathrm{E}}$ with $\mathrm{n}$ outcomes each of which has a probability that is a multiple of $1 / \mathrm{n}$.

For $F \in D_{n}^{E}$, let us list the mass-points of $F$ in non-decreasing order as $x_{1}^{F}, \ldots, x_{n}^{F}$. By the axioms of ordering and continuity on $D_{n}^{E}$, we can represent preferences by a numerical indicator $V_{n}^{E}(F) \equiv U_{n}\left(x_{1}, \ldots, x_{n}\right)$. The domain of $U_{n}$ is the $n$-fold Cartesian product of $X$, subject to the constraints that $x_{1} \leq \ldots \leq x_{n}$. Let us denote this space $X^{n}$. The subsets of components $\{i \mid 1 \leq i \leq j\}$ and $\{i \mid j \leq i \leq n\}$ are separable in Gorman's sense, by virtue of the ordinal independence assumption.

\section{$\underline{\text { Lemma }}$}

If $\succeq$ satisfies ordering, continuity and ordinal independence on $D_{n}^{E}$, then there exist $u_{i}^{n}, i=1, \ldots, n$, such that

$$
\sum_{\mathrm{i}=1}^{\mathrm{n}} \mathrm{u}_{\mathrm{i}}^{\mathrm{n}}\left(\mathrm{x}_{\mathrm{i}}^{\mathrm{F}}\right)
$$

is a numerical representation of $\succeq$. Moreover $u_{i}^{n}$ is continuous and non-decreasing. Proof of lemma: int $X^{n}$ can be written as the union of open rectangles $\left\{S_{k}\right\}_{k=1, \ldots}$ where

$$
\mathrm{S}_{\mathrm{k}} \subseteq \mathbb{R}^{\mathrm{n}}
$$

and where, for any $k, S_{k} \cap\left(\bigcup_{j=1}^{k-1} S_{j}\right) \neq \phi$.

Apply Gorman's theorem to $\mathrm{S}_{1}$, obtaining a representation

$$
\mathrm{U}_{\mathrm{n}}\left(\mathrm{x}_{1}, \ldots \mathrm{x}_{\mathrm{n}}\right)=\sum_{\mathrm{i}=1}^{\mathrm{n}} \mathrm{u}_{\mathrm{i}}\left(\mathrm{x}_{\mathrm{i}}\right), \quad \mathrm{x} \in \mathrm{S}_{1}
$$


where $u_{i}$ are continuous and non-decreasing, by virtue of the continuity and monotonicity axioms.

Now apply Gorman's theorem to $\mathrm{S}_{2}$ obtaining

$$
\mathrm{U}_{\mathrm{n}}\left(\mathrm{x}_{1}, \ldots, \mathrm{x}_{\mathrm{n}}\right)=\sum_{\mathrm{i}=1}^{\mathrm{n}} \tilde{\mathrm{u}}_{\mathrm{i}}\left(\mathrm{x}_{\mathrm{i}}\right), \quad \mathrm{x} \in \mathrm{S}_{2} .
$$

The functions $u_{i}$ are unique up to common affine transformations. Therefore there will be a unique set of functions $\tilde{u}_{i}$ which agree with the $u_{i}$ on their common domain $S_{1} \cap S_{2}$. With only a slight abuse of notation we can use $u_{i}$ to denote these functions throughout the domain $\mathrm{S}_{1} \cup \mathrm{S}_{2}$. Continuing this procedure, and extending continuously to the boundary of $\mathrm{X}^{\mathrm{n}}$, we obtain (3.1). Q.E.D.

Define

$$
\psi^{\mathrm{n}}: \mathrm{X} \times\left\{0, \frac{1}{\mathrm{n}}, \frac{2}{\mathrm{n}}, \ldots, 1\right\} \rightarrow \mathbb{R}
$$

by

$$
\begin{gathered}
\psi^{\mathrm{n}}\left(\mathrm{x}, \frac{\mathrm{k}}{\mathrm{n}}\right)=\sum_{\mathrm{i}=1}^{\mathrm{k}} \mathrm{u}_{\mathrm{i}}^{\mathrm{n}}(\mathrm{x}) \\
\text { and } \psi^{\mathrm{n}}(\mathrm{x}, 0)=0 \\
\text { Since } \psi^{\mathrm{n}}\left(\mathrm{x}_{\mathrm{i}}^{\mathrm{F}}, \frac{\mathrm{i}}{\mathrm{n}}\right)-\psi^{\mathrm{n}}\left(\mathrm{x}_{\mathrm{i}}^{\mathrm{F}}, \frac{\mathrm{i}-1}{\mathrm{n}}\right)=\mathrm{u}_{\mathrm{i}}^{\mathrm{n}}\left(\mathrm{x}_{\mathrm{i}}^{\mathrm{F}}\right) \text { for } \mathrm{i}=1, \ldots, \mathrm{n}
\end{gathered}
$$

we have

$$
\begin{gathered}
\sum_{i=1}^{\mathrm{n}} \psi^{\mathrm{n}}\left(\mathrm{x}_{\mathrm{i}}^{\mathrm{F}}, \frac{\mathrm{i}}{\mathrm{n}}\right)-\psi^{\mathrm{n}}\left(\mathrm{x}_{\mathrm{i}}^{\mathrm{F}}, \frac{\mathrm{i}-1}{\mathrm{n}}\right) \\
=\sum_{\mathrm{i}=1}^{\mathrm{n}} \mathrm{u}_{\mathrm{i}}^{\mathrm{n}}\left(\mathrm{x}_{\mathrm{i}}^{\mathrm{F}}\right)
\end{gathered}
$$


and that it also represents $\succeq$ on $\mathrm{D}_{\mathrm{n}^{\mathrm{E}}}^{\mathrm{E}}$.

Note that if $m=j n$ for some integer $j$, then

$$
\psi^{\mathrm{m}}\left(\mathrm{x}, \frac{\mathrm{k}}{\mathrm{n}}\right)=\psi^{\mathrm{n}}\left(\mathrm{x}, \frac{\mathrm{k}}{\mathrm{n}}\right)
$$

Therefore, applying the above definition for all $n$, we obtain a function

$$
\psi: X \times \mathbf{Q} \rightarrow \mathbb{R}
$$

where $\mathbf{Q}$ is the set of all rational numbers in $[0,1]$.

Define $\tilde{\psi}(\mathrm{x}, \mathrm{q})=\psi(\mathrm{x}, \mathrm{q})-\psi(\overline{\mathrm{x}}, \mathrm{q})$.

\section{Lemma}

If $\mathrm{F} \in \mathrm{D}^{\mathrm{E}}$ has mass points with rational probabilities, then $\mathrm{V}(\mathrm{F})=\sum_{\mathrm{i}=1}^{\mathrm{n}} \tilde{\psi}\left(\mathrm{x}_{\mathrm{i}}^{\mathrm{F}}, \mathrm{q}_{\mathrm{i}}\right)-\tilde{\psi}\left(\mathrm{x}_{\mathrm{i}}^{\mathrm{F}}, \mathrm{q}_{\mathrm{i}-1}\right)$ represents $\succeq$, where $\mathrm{q}_{\mathrm{i}}$ is the cumulative at $\mathrm{x}_{\mathrm{i}}^{\mathrm{F}}$.

Proof of lemma: Let $F \in D^{E}$ have mass points at $x_{1}^{F}, \ldots x_{n}^{F}$, in increasing order,

$$
\begin{aligned}
& \sum_{\mathrm{i}=1}^{\mathrm{n}} \tilde{\psi}\left(\mathrm{x}_{\mathrm{i}}^{\mathrm{F}}, \mathrm{q}_{\mathrm{i}}\right)-\tilde{\psi}\left(\mathrm{x}_{\mathrm{i}}^{\mathrm{F}}, \mathrm{q}_{\mathrm{i}-1}\right) \\
= & \sum_{\mathrm{i}=1}^{\mathrm{n}} \psi\left(\mathrm{x}_{\mathrm{i}}^{\mathrm{F}}, \mathrm{q}_{\mathrm{i}}\right)-\psi\left(\mathrm{x}_{\mathrm{i}}^{\mathrm{F}}, \mathrm{q}_{\mathrm{i}-1}\right)-\sum_{\mathrm{i}=1}^{\mathrm{n}}\left(\psi\left(\overline{\mathrm{x}}, \mathrm{q}_{\mathrm{i}}\right)-\psi\left(\overline{\mathrm{x}}, \mathrm{q}_{\mathrm{i}-1}\right)\right)
\end{aligned}
$$

However the last summation is invariant to $\left(\mathrm{q}_{1}, \ldots, \mathrm{q}_{\mathrm{n}}\right)$ and hence to $\mathrm{F}$, because it represents the utility of a unit point mass at $\bar{x}$. Thus the left-hand side of (3.3) is also a representation of $\succeq$.

\section{Lemma}

$$
\tilde{\psi} \text { is continuous. }
$$




\section{Proof of lemma}

Let $F$ be the distribution: $x_{1}$ with probability $q$ and $\bar{x}$ with probability $1-q$ (denoted $\left(\mathrm{x}_{1}, \overline{\mathrm{x}}, \mathrm{q}, 1-\mathrm{q}\right)$ ) where $\mathrm{q}$ is rational. We have

$$
\mathrm{V}(\mathrm{F})=\tilde{\psi}\left(\mathrm{x}_{1}, \mathrm{q}\right)-\tilde{\psi}(\mathrm{x}, 0)+\tilde{\psi}(\overline{\mathrm{x}}, 1)-\tilde{\psi}(\overline{\mathrm{x}}, \mathrm{q})
$$

which equals

$$
\begin{gathered}
\mathrm{V}(\mathrm{F})=\psi\left(\mathrm{x}_{1}, \mathrm{q}\right)-\psi(\overline{\mathrm{x}}, \mathrm{q}) \\
\text { or } \tilde{\psi}\left(\mathrm{x}_{1}, \mathrm{q}\right)
\end{gathered}
$$

$\tilde{\psi}\left(\mathrm{x}_{1}, \mathrm{q}\right)$ is continuous in $\mathrm{x}_{1}$ from the continuity of the $u_{\mathrm{n}}^{\mathrm{i}}$ 's.

Suppose now that a sequence of rational numbers $q_{k}$ converges to $q$ and that $\tilde{\psi}\left(\mathrm{x}_{1}, \mathrm{q}_{\mathrm{k}}\right)$ does not converge to $\tilde{\psi}\left(\mathrm{x}_{1}, \mathrm{q}\right)$, say it converges to $\tilde{\psi}\left(\mathrm{x}_{1}, \mathrm{q}\right)-\alpha$, where $\alpha>0$. There exists some $\epsilon>0$ such that

$$
\tilde{\psi}\left(\mathrm{x}_{1}, \mathrm{q}\right)-\frac{\alpha}{2}<\tilde{\psi}\left(\mathrm{x}_{1}-\mathrm{f}, \mathrm{q}\right)<\tilde{\psi}\left(\mathrm{x}_{1}, \mathrm{q}\right)
$$

For $\mathrm{k}$ large enough, the distribution $\left(\mathrm{x}_{1}-\epsilon, \overline{\mathrm{x}}, \mathrm{q}, 1-\mathrm{q}\right)$ is strictly preferred to the distribution $\left(\mathrm{x}_{1}, \overline{\mathrm{x}}, \mathrm{q}_{\mathrm{k}}, 1-\mathrm{q}_{\mathrm{k}}\right)$, which contradicts the continuity assumption. Q.E.D.

Since $V(F)$ is continuous on the distributions with rational probabilities, it has a continuous extension $\tilde{\mathrm{V}}(\mathrm{F})$ on $\mathrm{D}$.

Since $\tilde{\psi}$ is continuous, it has a unique continuous extension to $\mathrm{X} \times[0,1]$, denoted $\bar{\psi}$. Moreover, $\mathrm{V}(\mathrm{F})=\sum_{\mathrm{i}=1}^{\mathrm{n}}\left[\bar{\psi}\left(\mathrm{x}_{\mathrm{i}}, \mathrm{p}_{\mathrm{i}}\right)-\bar{\psi}\left(\mathrm{x}_{\mathrm{i}}, \mathrm{p}_{\mathrm{i}-1}\right)\right]$ where $\mathrm{F}$ is the distribution with support $\left\{x_{1}, \ldots, x_{n}\right\}$ and cumulative $p_{i}$ at $x_{i}$.

The function $\bar{\psi}$ induces a continuous measure on the Borel sets of 
$\mathrm{X} \times[0,1]$ as follows: Consider the function $\mu$ induced on rectangles $\left[\mathrm{x}_{1}, \mathrm{x}_{2}\right] \times\left[\mathrm{p}_{1}, \mathrm{p}_{2}\right]$ by

$$
\mu\left(\left[\mathrm{x}_{1}, \mathrm{x}_{2}\right] \times\left[\mathrm{p}_{1}, \mathrm{p}_{2}\right]\right)=\bar{\psi}\left(\mathrm{x}_{2}, \mathrm{p}_{2}\right)-\bar{\psi}\left(\mathrm{x}_{2}, \mathrm{p}_{1}\right)-\bar{\psi}\left(\mathrm{x}_{1}, \mathrm{p}_{2}\right)+\bar{\psi}\left(\mathrm{x}_{1}, \mathrm{p}_{1}\right)
$$

and let $\bar{\mu}$ be its Lebesgue extension to all Borel sets in $\mathrm{X} \times[0,1]$.

Now as $\bar{\psi}$ is continuous, $\bar{\mu}$ will be continuous, in the sense that it has no point-mass.

By construction of the Lebesgue extension, the measure is set-continuous: That is, if $A_{n} \rightarrow A$ then $\mu\left(A_{n}\right) \rightarrow \mu(A)$ where $A_{n} \rightarrow A$ means $\limsup A_{n}=\liminf A_{n}=A$.

Let us define now $A_{F}=\{(x, p) \mid p \geq F(x)\}$. It is easy to construct, for each distribution $F$, a sequence of simple distributions such that $A_{n} \rightarrow A_{F}\left(A_{n}\right.$ and $A$ are the upper set), and $A_{n} \subseteq A_{n-1}$ and $A_{F} \subseteq A_{n}$. For a simple distribution:

$$
\begin{aligned}
\bar{\mu}\left(\mathrm{A}_{\mathrm{n}}\right) & =\sum_{\mathrm{i}=1}^{\mathrm{n}}\left[\bar{\psi}\left(\mathrm{x}_{\mathrm{i}}, \mathrm{p}_{\mathrm{i}}\right)-\bar{\psi}\left(\mathrm{x}_{\mathrm{i}}, \mathrm{p}_{\mathrm{i}-1}\right)\right]-\sum_{\mathrm{i}=1}^{\mathrm{n}}\left[\bar{\psi}\left(0, \mathrm{p}_{\mathrm{i}}\right)-\bar{\psi}\left(0, \mathrm{p}_{\mathrm{i}-1}\right)\right] \\
& =\tilde{\mathrm{V}}\left(\mathrm{F}_{\mathrm{n}}\right)-\sum_{\mathrm{i}=1}^{\mathrm{n}} \tilde{\psi}\left(0, \mathrm{p}_{\mathrm{i}}\right)+\sum_{\mathrm{i}=1}^{\mathrm{n}-1} \tilde{\psi}\left(0, \mathrm{p}_{\mathrm{i}}\right) \\
& =\tilde{\mathrm{V}}\left(\mathrm{F}_{\mathrm{n}}\right)-\tilde{\psi}(0,1)
\end{aligned}
$$

so for any $\mathrm{F}, \bar{\mu}\left(\mathrm{A}_{\mathrm{F}}\right)=\tilde{\mathrm{V}}(\mathrm{F})-\tilde{\psi}(0,1)$

We can take $\bar{\mu}\left(\mathrm{A}_{\mathrm{F}}\right)$ as representation of the preference.

Now decompose $\bar{\mu}(\mathrm{dp}, \mathrm{dx})$ as a marginal measure $\mu(\mathrm{dp})$ and a conditional distribution $\mu_{2}(\mathrm{p}, \mathrm{dx})$. 


$$
\bar{\mu}(\mathrm{A})=\int \mu(\mathrm{dp}) \int \mu_{2}(\mathrm{p}, \mathrm{dx})
$$

where the integral is taken over $(p, x) \in A_{F}$ Write

$$
\left\{\mathrm{x} \mid(\mathrm{p}, \mathrm{x}) \in \mathrm{A}_{\mathrm{F}}\right\}=[0, \mathrm{z}(\mathrm{p})]
$$

define

$$
\bar{\phi}(\mathrm{z}(\mathrm{p}), \mathrm{p})=\int_{0}^{\mathrm{z}(\mathrm{p})} \mu_{2}(\mathrm{p}, \mathrm{dx})
$$

Then

$$
\bar{\mu}\left(\mathrm{A}_{\mathrm{F}}\right)=\int \bar{\phi}(\mathrm{z}(\mathrm{p}), \mathrm{p}) \mu(\mathrm{dp}) .
$$

The corollary is obtained by decomposing the measure into the marginal measure $\nu(\mathrm{dx})$ and the conditional measure $\nu_{2}(\mathrm{p}, \mathrm{dx})$.

Proof of Theorem 5.2: $(\phi, \mathrm{h})$ is more risk averse than $\left(\phi^{*}, \mathrm{~h}^{*}\right)$ if and only if the function $\mathrm{x} \rightarrow \int_{0}^{\mathrm{x}} \phi_{1}(\mathrm{~s}, \mathrm{~F}(\mathrm{~s})) \mathrm{ds}$ is a concave transform of the function $\mathrm{x} \rightarrow \int_{0}^{\mathrm{x}} \phi_{1}^{*}(\mathrm{~s}, \mathrm{~F}(\mathrm{~s})) \mathrm{ds}$, for all F.

From Pratt's characterization of concave transforms, this is equivalent to:

$$
\forall \mathrm{F}, \forall \mathrm{x}_{1}, \mathrm{x}_{2}, \mathrm{x}_{3}, \mathrm{x}_{1}<\mathrm{x}_{2}<\mathrm{x}_{3}
$$

$$
\frac{\int_{\mathrm{x}_{1}}^{\mathrm{x}_{2}} \phi_{1}(\mathrm{~s}, \mathrm{~F}(\mathrm{~s})) \mathrm{ds}}{\int_{\mathrm{x}_{1}}^{\mathrm{x}_{2}} \phi_{1}^{*}(\mathrm{~s}, \mathrm{~F}(\mathrm{~s})) \mathrm{ds}} \geq \frac{\int_{\mathrm{x}_{2}}^{\mathrm{x}_{3}} \phi_{1}(\mathrm{~s}, \mathrm{~F}(\mathrm{~s})) \mathrm{ds}}{\int_{\mathrm{x}_{2}}^{\mathrm{x}_{3}} \phi_{1}^{*}(\mathrm{~s}, \mathrm{~F}(\mathrm{~s})) \mathrm{ds}}
$$

Taking the limit when $\mathrm{x}_{2} \rightarrow \mathrm{x}_{1}$ and the limit when $\mathrm{x}_{2} \rightarrow \mathrm{x}_{3}$ we find when $\mathrm{F}$ is continuous:

$$
\frac{\phi_{1}\left(\mathrm{x}_{1}, \mathrm{~F}\left(\mathrm{x}_{1}\right)\right)}{\phi_{1}^{*}\left(\mathrm{x}_{1}, \mathrm{~F}\left(\mathrm{x}_{1}\right)\right)} \geq \frac{\int_{\mathrm{x}_{1}}^{\mathrm{x}_{3}} \phi_{1}(\mathrm{~s}, \mathrm{~F}(\mathrm{~s})) \mathrm{ds}}{\int_{\mathrm{x}_{1}}^{\mathrm{x}_{3}} \phi_{1}^{*}(\mathrm{~s}, \mathrm{~F}(\mathrm{~s})) \mathrm{ds}} \geq \frac{\phi_{1}\left(\mathrm{x}_{3}, \mathrm{~F}\left(\mathrm{x}_{3}\right)\right.}{\phi_{1}^{*}\left(\mathrm{x}_{3}, \mathrm{~F}\left(\mathrm{x}_{3}\right)\right)}
$$


so that $\frac{\phi_{1}(\mathrm{x}, \mathrm{F}(\mathrm{x}))}{{ }^{*}(\mathrm{x}, \mathrm{F}(\mathrm{x}))}$ is non-increasing which is equivalent to our statement.

Suppose now that $\frac{\phi_{1}(\mathrm{x}, \mathrm{F}(\mathrm{x}))}{\phi_{1}(\mathrm{x}, \mathrm{F}(\mathrm{x})}$ is non-increasing then

$$
\frac{\int_{\mathrm{x}_{1}}^{\mathrm{x}_{2}} \phi_{1}(\mathrm{~s}, \mathrm{~F}(\mathrm{~s})) \mathrm{ds}}{\int_{\mathrm{x}_{1}}^{\mathrm{x}_{2}} \phi_{1}{ }^{*}(\mathrm{~s}, \mathrm{~F}(\mathrm{~s})) \mathrm{ds}} \geq \frac{\phi_{1}\left(\mathrm{x}_{2}, \mathrm{~F}\left(\mathrm{x}_{2}\right)\right)}{\phi_{1}\left(\mathrm{x}_{2}, \mathrm{~F}\left(\mathrm{x}_{2}\right)\right)} \geq \frac{\int_{\mathrm{x}_{2}}^{\mathrm{x}_{3}} \phi_{1}(\mathrm{~s}, \mathrm{~F}(\mathrm{~s})) \mathrm{ds}}{\int_{\mathrm{x}_{2}}^{\mathrm{X}_{3}} \phi_{1}{ }^{*}(\mathrm{~s}, \mathrm{~F}(\mathrm{~s})) \mathrm{ds}}
$$

QED

\section{Proof of Theorem $\underline{6.2}$ :}

\section{Necessity:}

$\frac{\mathrm{dp}_{3}}{\mathrm{dp_{1 }}}=\frac{\phi\left(\mathrm{x}_{2}, \mathrm{p}_{1}\right)-\phi\left(\mathrm{x}_{1}, \mathrm{p}_{1}\right)}{\phi\left(\mathrm{x}_{3}, 1-\mathrm{p}_{3}\right)-\phi\left(\mathrm{x}_{2}, 1-\mathrm{p}_{3}\right)} \quad$ must be non-increasing with $\mathrm{p}_{1}$, which

implies $\quad \phi_{12}(\mathrm{x}, \mathrm{p}) \leq 0$.

Sufficiency:

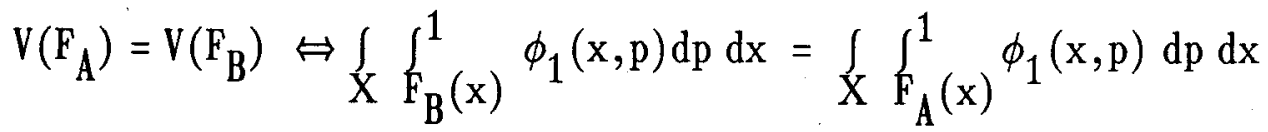

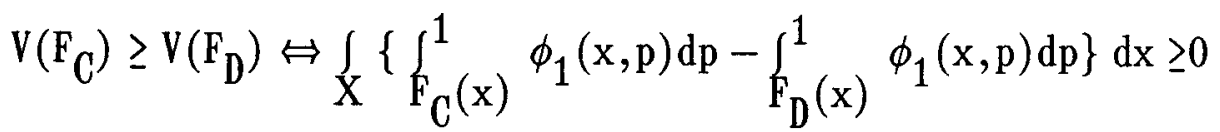

$$
\begin{aligned}
& \Leftrightarrow \quad \int_{x<x^{*}}\left\{\int_{F_{C^{\prime}}(x)}^{F_{A}(x)} \phi_{1}(x, p) d p-\int_{F_{D}}(x) \phi_{1}(x, p) d p\right\} d x \geq 0
\end{aligned}
$$




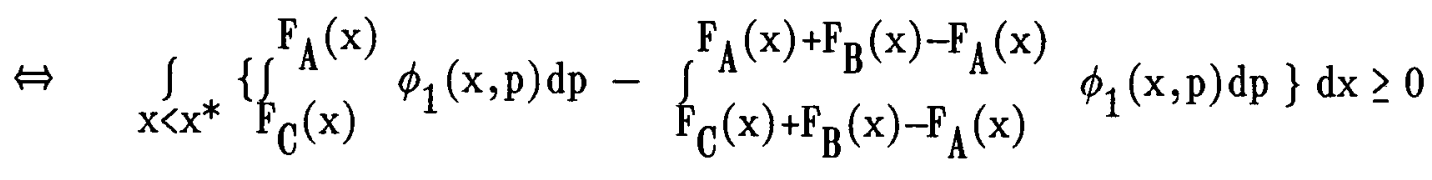

$\Leftrightarrow \quad \int_{x<x^{*}} \int_{F_{C}(x)}^{F_{A}(x)}\left\{\phi_{1}(x, p)-\phi_{1}\left(x, p+F_{B}(x)-F_{A}(x)\right)\right\} d p d x \geq 0$.

As for $\mathrm{x} \leq \mathrm{x}^{*}, \mathrm{~F}_{\mathrm{C}}(\mathrm{x}) \leq \mathrm{F}_{\mathrm{A}}(\mathrm{x})$ and $\mathrm{F}_{\mathrm{B}}(\mathrm{x})-\mathrm{F}_{\mathrm{A}}(\mathrm{x}) \geq 0$, this is true if $\phi_{1}(\mathrm{x}, \mathrm{p})$ is non-increasing with $\mathrm{p}$ or $\phi_{12}(\mathrm{x}, \mathrm{p}) \leq 0$. Q.E.D.

\section{Proof of Theorem 7.1:}

We call $F_{P}$ the distribution $\left(w-\epsilon, w+\frac{1-p}{p} \epsilon, 1-p, p\right)$.

$V\left(G_{W}\right)=\int_{0}^{1} \phi(w, s) d s$

$\mathrm{V}\left(\mathrm{F}_{\mathrm{p}}\right)=\int_{0}^{1-\mathrm{p}} \phi(\mathrm{w}-\epsilon, \mathrm{s}) \mathrm{ds}+\int_{1-\mathrm{p}}^{1} \phi\left(\mathrm{w}+\frac{1-\mathrm{p}}{\mathrm{p}} \epsilon, \mathrm{s}\right) \mathrm{ds}$

$\lim _{\mathrm{p} \rightarrow 0} \sup V\left(\mathrm{~F}_{\mathrm{p}}\right)=\int_{0}^{1} \phi(\mathrm{w}-\mathrm{\epsilon}, \mathrm{s}) \mathrm{ds}+\underset{\mathrm{p} \rightarrow 0}{\lim \sup } \int_{1-\mathrm{p}}^{1} \phi\left(\mathrm{w}+\frac{1-\mathrm{p}}{\mathrm{p}} \epsilon, \mathrm{s}\right) \mathrm{ds}$

Suppose that $\mathrm{p}_{\mathrm{n}} \stackrel{\mathrm{n} \rightarrow+\infty}{\longrightarrow} 0$ and $\mathrm{V}\left(\mathrm{G}_{\mathrm{w}}\right) \leq \mathrm{V}\left(\mathrm{F}_{\mathrm{p}_{\mathrm{n}}}\right)$

Then there exists $a>0$, such that for all $n$ :

(1) $\underset{1-\mathrm{p}_{\mathrm{n}}}{\int^{1}} \phi\left(w+\frac{1-\mathrm{p}_{\mathrm{n}}}{\mathrm{p}_{\mathrm{n}}} \epsilon, \mathrm{s}\right) \mathrm{ds} \geq 2 \mathrm{a}$

Now choose the sequence $q_{t}$ by: $q_{1}=p_{1}, q_{t+1}=p_{n}$ such that 
$\int_{1-q_{t}}^{1-q_{t+1}} \phi\left(w+\frac{1-q_{t}}{q_{t}} \epsilon, s\right) d s>a$. Given that $q_{t}=p_{n}$ for some $n$, the inequality

insures that we can find $\mathrm{q}_{t+1}$. Choose a distribution $\mathrm{F}$ as follows:

$z(p)=w+\frac{1-q_{t}}{q_{t}} \in$ if $\left.p \in\right] 1-q_{t}, 1-q_{t+1}[$. Then

$V(F) \geq \sum_{t=1}^{\infty} \int_{1-q_{t}}^{1-q_{t+1}} \phi\left(w+\frac{1-q_{t}}{q_{t}} \epsilon, s\right) d s=+\infty$

So the preferences are unbounded.

Q.E.D.

Proof of Lemma (7.2):

Define $F_{p}(x)=(1-p) F\left(x+\frac{p}{1-p} \epsilon\right)+p F(x-\epsilon)$.

$$
\begin{aligned}
& V\left(F_{p}\right)-V(F)=\int_{X} \int_{p}^{F(x)^{\circ}} \phi_{1}(x, s) d s \\
& =\int_{X}\left\{\int_{(1-p) F(x)+p F(x-\epsilon)} \phi_{1}(x, s) d s+\int_{(x)}^{F(x)} \phi_{1}(x, s) d s\right. \\
& +\int_{F(x)}^{(1-p) F(x)+p F(x-\epsilon)} \quad F\left(x+\frac{p}{1-p} \epsilon\right) \\
& \left.\phi_{1}(x, s) d s+\int_{(1-p) F\left(x+\frac{p}{1-p} \epsilon\right)+p F(x-\epsilon)} \phi_{1}(x, s) d s\right\} d x
\end{aligned}
$$


a) The second line has derivative 0 at $p=0$.

$$
\forall \propto>0, \exists \beta>0 /|\mathrm{s}-\mathrm{F}(\mathrm{x})|<\mathrm{p} \Rightarrow\left|\phi_{1}(\mathrm{x}, \mathrm{s})-\phi_{1}(\mathrm{x}, \mathrm{F}(\mathrm{x}))\right|<\alpha .
$$

Define $G(p)=\int_{X}\left\{\begin{array}{l}(1-p) F(x)+p F(x-\epsilon) \\ \int_{1}(x, s) d s+\end{array} \underset{(1-p) F\left(x+\frac{p}{1-p} \epsilon\right)+p F(x-\epsilon)}{F\left(x+\frac{p}{1-p} \epsilon\right)} \phi_{1}(x, s) d s\right\} d x$

$$
\begin{aligned}
& \int_{X} \phi_{1}(x, F(x))\left(F\left(x+\frac{p}{1-p} \epsilon\right)-F(x)\right) d x+2 \alpha \int_{X}(F(x)-F(x-\epsilon)) d x \\
& \geq \frac{G(p)}{p} \geq \int_{X} \phi_{1}(x, F(x))\left(F\left(x+\frac{p}{1-p} \epsilon\right)-F(x)\right) d x-2 \alpha \int_{X}(F(x)-F(x-\epsilon)) d x
\end{aligned}
$$

using the right continuity of $\mathrm{F}$, we find

$\forall \propto \quad 2 \propto \int_{X}(F(x)-F(x-\epsilon)) d x \geq \lim _{p \rightarrow 0}\left|\frac{G(p)}{p}\right|$ or $\lim _{p \rightarrow 0} \frac{G(p)}{p}=0$.

b) The first term of the first line is $V\left((1-p) F+p F_{\epsilon}\right)-V(F)$ where $F_{\epsilon}$ is the distribution $F_{\epsilon}(x)=F(x-\epsilon)$. By definition of $U_{F}$ its derivative is:

$$
\int_{X} U_{F}(x)\{d F(x-\epsilon)-d F\}=E_{F}\left\{U_{F}(x+\epsilon)-U_{F}(x)\right\}
$$

The second term can be written:

$$
\int_{X} \int_{F(x)+\frac{p}{1-p} \epsilon}^{F(x)} \phi_{1}(x, s) d s d x=\int_{S}\left\{\phi\left(z(s)-\frac{p}{1-p} \epsilon, s\right)-\phi(z(s), s)\right\} d s
$$

Its derivative at $\mathrm{p}=0$ is $-\epsilon \int_{\mathrm{S}} \phi_{1}(\mathrm{z}(\mathrm{s}), \mathrm{s}) \mathrm{ds}$.

So the overall derivative is 


$$
\mathrm{E}_{\mathrm{F}}\left\{\mathrm{U}_{\mathrm{F}}(\mathrm{x}+\epsilon)-\mathrm{U}_{\mathrm{F}}(\mathrm{x})\right\}-\epsilon \int_{\mathrm{S}} \phi_{1}(\mathrm{z}(\mathrm{s}), \mathrm{s}) \mathrm{ds}
$$

Lemma (7.2) follows directly.

\section{Proof of Lemma (7.3):}

Define $F_{p}(x)=F(x+p \epsilon)$ the distribution of the agent if he insures the risk.

$$
\begin{aligned}
& V\left(F_{p}\right)-V(G)=\int_{X} \int_{f(x+p \epsilon)}^{p F(x+\epsilon)+(1-p) F(x)} \phi_{1}(x, s) d s \\
& =\int_{X} f(x)
\end{aligned}
$$

The first term is just $V(F)-V\left((1-p) F+p F_{\epsilon}\right)$ where $F_{\epsilon}(x)=F(x+\epsilon)$, its derivative is

$$
\int \mathrm{U}_{\mathrm{F}}(\mathrm{x})\{\mathrm{dF}(\mathrm{x})-\mathrm{dF}(\mathrm{x}+\epsilon)\}=\mathrm{E}_{\mathrm{F}}\left\{\mathrm{U}_{\mathrm{F}}(\mathrm{x})-\mathrm{U}_{\mathrm{F}}(\mathrm{x}-\epsilon)\right\} .
$$

The second term is $\int_{\mathrm{S}}\{-\phi(\mathrm{z}(\mathrm{s}), \mathrm{s})+\phi(\mathrm{z}(\mathrm{s})-\mathrm{p} \epsilon, \mathrm{s})\} \mathrm{ds}$,

its derivative is $-\epsilon \int_{\mathrm{S}} \phi_{1}(\mathrm{z}(\mathrm{s}), \mathrm{s}) \mathrm{ds}$. So the total derivative is:

$$
\mathrm{E}_{\mathrm{F}}\left(\mathrm{U}_{\mathrm{F}}(\mathrm{x})-\mathrm{U}_{\mathrm{F}}(\mathrm{x}-\epsilon)\right)-\epsilon \int_{\mathrm{S}} \phi_{1}(\mathrm{z}(\mathrm{s}), \mathrm{s}) \mathrm{ds}
$$




\section{Proof of Theorem $\underline{8.1}$ :}

For $F=G_{w}$ the relation (7.a) reduces to :

(i) $\frac{\phi(w+\epsilon, 1)-\phi(w, 1)}{\epsilon} \geq \int_{0}^{1} \phi_{1}(w, p) d p$

Since $\phi_{12}(\mathrm{w}, \mathrm{p})<0, \int_{0}^{1} \phi_{1}(\mathrm{w}, \mathrm{p}) \mathrm{dp}>\phi_{1}(\mathrm{w}, 1)$. Choose w arbitrarily, relation (1) implies that we can find $\epsilon_{1}>0$, such that:

$$
\begin{gathered}
\phi\left(\mathrm{w}+\epsilon_{1}, 1\right)-\phi(\mathrm{w}, 1) \geq \epsilon_{1} \int_{0}^{1} \phi_{1}(\mathrm{w}, \mathrm{p}) \mathrm{dp}>\epsilon_{1} \phi_{1}(\mathrm{w}, 1) \\
\phi_{1}\left(\mathrm{w}+\epsilon_{1}, 1\right) \geq \phi_{1}(\mathrm{w}, 1)
\end{gathered}
$$

Recursively, define $\epsilon_{\mathrm{n}}$ by:

$$
\begin{gathered}
\phi\left(w+\epsilon_{1} \ldots .+\epsilon_{n}, 1\right)-\phi\left(w+\epsilon_{1} \ldots+\epsilon_{n-1}, 1\right) \geq \epsilon_{n} \int_{0}^{1} \phi_{1}\left(w+\ldots .+\epsilon_{n-1}\right) d p \\
\phi_{1}\left(1+\epsilon_{1} \ldots .+\epsilon_{n}, 1\right) \geq \phi_{1}\left(w+\ldots+\epsilon_{n-1}, 1\right)
\end{gathered}
$$

Then $\phi\left(\mathrm{w}+\ldots+\epsilon_{\mathrm{n}}, 1\right)-\phi(\mathrm{w}, 1)>\phi_{1}(\mathrm{w}, 1)\left[\epsilon_{1} \ldots+\epsilon_{\mathrm{n}}\right]$.

Suppose that $\phi(\mathrm{x}, 1)$ is bounded, then $\mathrm{w}+\epsilon_{1} \ldots+\epsilon_{\mathrm{n}}$ must converge to some $\overline{\mathrm{w}}$.

But then $\int_{0}^{1} \phi_{1}\left(w+\epsilon_{1} \ldots+\epsilon_{n-1}, p\right) d p \underset{n \rightarrow+\infty}{\longrightarrow} \int_{0}^{1} \phi_{1}(\bar{w}, p) d p$ 
while $\frac{\phi\left(w+\ldots \epsilon_{n}, 1\right)-\phi\left(w+\epsilon_{1} \ldots+\epsilon_{n-1}, 1\right)}{\epsilon_{n}} \underset{n \rightarrow+\infty}{ } \phi_{1}(\bar{w}, 1)$

So we find $\phi_{1}(\bar{w}, 1) \geq \int_{0}^{1} \phi_{1}(\bar{w}, p)$ dp which contradicts $\phi_{12}(x, p)<0$. Therefore $\phi(x, 1)$ is unbounded. Since $\phi(\mathrm{x}, \mathrm{p})=\int_{0}^{\mathrm{x}} \phi_{1}(\mathrm{~s}, \mathrm{p}) \mathrm{ds}>\int_{0}^{\mathrm{x}} \phi_{1}(\mathrm{~s}, 1) \mathrm{ds}=\phi(\mathrm{x}, 1), \phi(\mathrm{x}, \mathrm{p})$ is unbounded for all $\mathrm{p}$. Q.E.D. 


\section{REFERENCES}

Chew, S.H., and L.G. Epstein, (1987), "A Unifying Approach to Axiomatic Non-Expected Utility Theories", mimeo, University of Toronto.

Chew, S.H., E. Karni and Z. Safra, (1987), "Risk Aversion in the Theory of Expected Utility with Rank-Dependent Probabilities," Journal of Economic Theory, 42, $370-381$.

Chew, S.H. and K. R. MacCrimmon (1979), "Alpha Utility Theory: A Generalization of Expected Utility Theory," Faculty of Commerce and Business Administration Working Paper \#669, University of British Columbia.

Dekel, E. (1986), "An Axiomatic Characterization of Preferences under Uncertainty: Weakening the Independence Axiom," Journal of Economic Theory, 40, 304-318.

Gorman, W.M. (1968), "The Structure of Utility Functions", 35, Review of Economic Studies, 367-390.

Gul, F. (1988), "Neo-Bernoullian Extensions and the Expected Utility Hypotheses and a Theory of Disappointment", mimeo., Stanford Graduate School of Business.

Friedman, M. and L. J. Savage (1948), "The Utility Analysis of Choices Involving Risk", Journal of Political Economy, 56, 279-304.

Kahneman, D. and A., Tversky (1984), "Choices, Values and Frames", American Psychologist, $\underline{39}, 341-350$.

Kahneman, D. and A., Tversky (1979), "Prospect Theory: An Analysis of Decision under Risk", Econometrica, 47, 263-291.

Loomes, G. and R. Sugden (1982), "Regret Theory: An Alternative Theory of Rational Choice under Uncertainty", Economic Journal, $\underline{92}$, 805-824.

Machina, M. (1982), "'Expected Utility' Analysis without the Independence Axiom", Econometrica, 50, 277-323.

MacCrimmon, K. and S. Larsen (1979), "Utility Theory: Axioms versus 'Paradoxes'", in Expected Utility Hypotheses and the Allais Paradox, M. Allais and O. Hager (eds.) Holland: D. Reidel.

Quiggin, J. (1982), "A Theory of Anticipated Utility," Journal of Economic Behavior and Organization, 3, 323-343.

Royden, H. (1963), Real Analysis, Macmillan, New York.

Segal, U. (1987). "Two-Stage Lotteries without the Reduction Axiom", University of Toledo working paper no. 8708 . 
Segal, U. (1984), "Nonlinear Decision Weights With the Independence Axiom," UCLA Working Paper \#353.

Yaari, M. (1987), "The Dual Theory of Choice Under Risk," Econometrica, 55, 96-115. 